\title{
Condensation and Evaporation of R32/R1234ze(E) and R744/R32/R1234ze(E) Flow in Horizontal Microfin Tubes
}

\author{
Chieko KONDOU ${ }^{1}$, Fumiya MISHIMA ${ }^{2}$, Shigeru KOYAMA ${ }^{2,3}$ \\ ${ }^{1}$ Nagasaki University, Graduate School of Engineering, Nagasaki, Japan \\ ${ }^{2}$ Kyushu University, Interdisciplinary Graduate School of Engineering Science, Fukuoka, Japan \\ ${ }^{3}$ Kyushu University, International Institute for Carbon-Neutral Energy Research, Fukuoka, Japan
}

The heat transfer characteristics of a low global warming potential (GWP) refrigerant mixture $R 744 / R 32 / R 1234 z e(E)$ in a horizontal microfin tube were investigated in this study. The condensation heat transfer coefficient of $R 744 / R 32 / R 1234 z e(E)(9 / 29 / 62$ mass\%) is somewhat lower than that of other mixtures, R744/R32/R1234ze(E)(4/43/53 mass\%), R32/R1234ze(E)(40/60 mass\%), and (30/70 mass\%), at an average saturation temperature of $40{ }^{\circ} \mathrm{C}$, mass flux of $200 \mathrm{~kg} \mathrm{~m}^{-2} \mathrm{~s}^{-1}$, and heat flux of $10 \mathrm{kWm}^{-2}$. The temperature glides of R744/R32/R1234ze(E)(9/29/62 mass\%), (4/43/53 mass\%), R32/R1234ze(E)(30/70 mass\%), and (40/60 mass\%) are 18, 11,10 , and $8 \mathrm{~K}$, respectively, at $40{ }^{\circ} \mathrm{C}$. Likewise, the magnitude of the heat transfer coefficient decrease strongly is affected by the temperature glide. The data for the evaporation heat transfer coefficient indicated similar effects of the temperature glide. At an average saturation temperature of $10{ }^{\circ} \mathrm{C}$, the evaporation heat transfer coefficient of $R 744 / R 32 / R 1234 z e(E)$ (9/29/62 mass\%) is slightly lower than that of other mixtures. The temperature glides of R744/R32/R1234ze(E)(9/29/62 mass\%), (4/43/53 mass\%), R32/R1234ze(E)(30/70 mass\%), and (40/60 mass\%) are 22, 13, 11, and $9 \mathrm{~K}$, respectively. The pressure gradients of these refrigerants are almost equal, and the difference is within the measurement uncertainty. The experimental pressure gradient agrees well with the predictions proposed for single components. (199 words) 


\section{Introduction}

Low global warming potential (GWP) refrigerant R1234ze(E) has been considered as an alternative to conventional refrigerant R410A for air conditioning systems. However, recently reported studies revealed that the coefficient of performance (COP) of systems using R1234ze(E) alone is unexpectedly lower than those using R410A. Because the volumetric capacity is much smaller than that of R410A, the cycle using R1234ze(E) requires a much higher volumetric flow rate with a larger compressor displacement or higher compressor speed to maintain the cooling/heating load, which results in a large pressure drop. The mixing of R744, R32, and R1234ze(E) has recently been attempted to increase the volumetric capacity while preserving the sub-300 100 year time horizon global warming potential (GWP 100$)$ (Koyama et al., 2013). The COP of the cycle using these ternary refrigerants has already been evaluated, and the feasibility was demonstrated with a drop-in experiment (Fukuda et al., 2014). The Air-Conditioning, Heating, and Refrigeration Institute (AHRI) leads an industry-wide cooperative research program, the Low Global Warming Potential Alternative Refrigerants Evaluation Program (Low-GWP AREP). In that program, COPs and cooling/heating capacities of R32/R1234ze(E) (73/27 mass\%) with a GWP ${ }_{100}$ of 494 and R744/R32/R1234ze(E) (60/6/34 mass\%) with a $\mathrm{GWP}_{100}$ of 407 were evaluated by drop-in and softoptimized system tests (Wang and Amrane, 2014). Nevertheless, the characteristics of the heat transfer and pressure drop of these refrigerants have not yet been clarified. As mentioned in many previous studies (e.g., Jacobs and Kruse, 1978; McLinden and Radermacher, 1987), exergy loss in heat exchangers can be minimized by utilizing the temperature glide of zeotropic mixtures. However, volatility differences result in severe degradation of the heat transfer coefficient (HTC), as investigated in numerous heat transfer studies (e.g., Jung and Radermacher, 1993; Niederküger and Steiner, 1994).

To understand the transport phenomenon of these ternary mixtures, the HTC and pressure gradients during the condensation and evaporation process in a horizontal microfin tube were experimentally investigated in this study. Experimental data of R744/R32/R1234ze(E) (4/43/53 mass\%) were compared to those of R32/R1234ze(E) (40/60 mass\%) as the combination of $\mathrm{GWP}_{100} \quad 300$; data on R744/R32/R1234ze(E) (9/29/62 mass\%) were compared to those of R32/R1234ze(E) (30/70 mass \%) as the combination of GWP 100200. 


\section{Experimental method}

Figure 1 (a) illustrates a vapor compression cycle that facilitated the measurement of the HTC and pressure gradients. The HTC and pressure gradients were measured in test sections (4) and (10) for condensation and evaporation, respectively. To determine the bulk enthalpies of superheated vapor, the bulk mean temperature and the pressure were measured in mixing chambers placed at the inlet of the desuperheater (3) and the outlet of the superheater (11). Additionally, the circulation composition of the mixture was measured by sampling approximately $1 \mathrm{cc}$ of subcooled liquid at the outlet of the liquid reservoir (6) just after the data were recorded. The sampled liquid was completely vaporized in the sampling vessel and then assayed by a thermal conductivity detector gas chromatograph. The refrigerant state was always evaluated at the circulation composition, but not the charge composition. Based on the bulk enthalpies of the superheated vapor, the enthalpies in the test sections were calculated by considering the enthalpy changes in the desuperheater and superheater obtained from the water side heat balance.

Figure 1 (b) illustrates the structure of test section (10) for the evaporation test. The structure of test section (4) for the condensation test was almost the same. A horizontally placed test microfin tube was surrounded by four water jackets, and $0.6 \mathrm{~mm}$ ID pressure ports were bored between the test sections to measure the heat transfer rates over the $414 \mathrm{~mm}$ length and pressure drops at $554 \mathrm{~mm}$ intervals. At the center of each subsection (i.e., the water jacket), 4 thermocouples were embedded on the top, bottom, right and left of the tube outer surface. The internal tube surface temperature, $T_{\mathrm{wi}}$, was obtained from the onedimensional heat conduction in the tube wall.

$$
\begin{gathered}
T_{\mathrm{wi}}=\left(T_{\mathrm{wo}, \text { top }}+T_{\mathrm{wo}, \text { bottom }}+T_{\mathrm{wo}, \text { right }}+T_{\mathrm{wo}, \text { left }}\right) / 4-\left[Q_{\mathrm{H} 2 \mathrm{O} \mathrm{TS}} /\left(2 \pi \Delta \mathrm{Z}_{\alpha} \lambda_{\text {tube }}\right)\right] \ln \left(D_{\mathrm{o}} / d_{\mathrm{eq}}\right) \\
\left(Q_{\mathrm{H} 2 \mathrm{O} \text { TS }}>0 \text { for condensation, } Q_{\mathrm{H} 2 \mathrm{O} \text { TS }}<0 \text { for evaporation }\right)
\end{gathered}
$$

where $Q_{\text {н2о тs }}$ is the heat transfer in a subsection, which is positive for the condensation test and negative for the evaporation test. $D Z_{\alpha}$ and $\lambda_{\text {tube }}$ are the active heat transfer length and thermalconductivity of the test

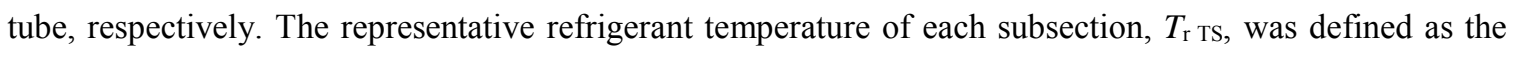
arithmetic mean of the inlet and outlet, calculated from the enthalpies and pressures by assuming thermodynamic equilibrium.

$$
T_{\mathrm{rTS}}=\left(T_{\mathrm{rTS}, \mathrm{i}}+T_{\mathrm{rTS}, \mathrm{o}}\right) / 2
$$




$$
\begin{aligned}
& T_{\mathrm{rTS}, \mathrm{i}}=f_{\text {equilibrium }}\left(h_{\mathrm{rTS}, \mathrm{i}}, P_{\mathrm{rTS}, \mathrm{i}}, X_{\mathrm{R} 744}, X_{\mathrm{R} 32}\right) \\
& T_{\mathrm{rTS}, \mathrm{o}}=f_{\text {equilibrium }}\left(h_{\mathrm{rTS}, \mathrm{o}}, P_{\mathrm{rTS}, \mathrm{o}}, X_{\mathrm{R} 744}, X_{\mathrm{R} 32}\right)
\end{aligned}
$$

where the subscripts "i" and "o" denote the inlet and outlet of the subsection, respectively. $X_{\mathrm{R} 744}$ and $X_{\mathrm{R} 32}$ are the measured circulation compositions of R744 and R32, respectively. Similarly, the representative vapor quality of each subsection, $x$, was calculated as follows:

$$
\begin{gathered}
x_{\mathrm{TS}}=\left(x_{\mathrm{TS}, \mathrm{i}}+x_{\mathrm{TS}, \mathrm{o}}\right) / 2 \\
x_{\mathrm{TS}, \mathrm{i}}=f_{\text {equilibrium }}\left(h_{\mathrm{rTS}, \mathrm{i}}, P_{\mathrm{rTS}, \mathrm{i}}, X_{\mathrm{R} 744}, X_{\mathrm{R} 32}\right) \\
x_{\mathrm{TS}, \mathrm{o}}=f_{\text {equilibrium }}\left(h_{\mathrm{rTS}, \mathrm{o}}, P_{\mathrm{rTS}, \mathrm{o}}, X_{\mathrm{R} 744}, X_{\mathrm{R} 32}\right)
\end{gathered}
$$

Table 1 specifies the dimensions of the test microfin tube based on the symbols in the microscopic cross sectional area of Figure 2. The equivalent inner diameter, $d_{\mathrm{eq}}$, is the diameter of a smooth tube that envelops an equal free flow volume. The surface enlargement, $\eta_{\mathrm{A}}$, is the ratio of the actual heat transfer area to that of the equivalent smooth tube. Based on the actual heat transfer area, the heat flux, $q$, and the HTC, $\alpha$, were defined as follows:

$$
\begin{gathered}
\alpha_{\mathrm{TS} 1}=q_{\mathrm{TS} 1} /\left(T_{\mathrm{rTS} 1}-T_{\mathrm{wi}}\right) \\
q_{\mathrm{TS} 1}=Q_{\mathrm{H} 2 \mathrm{O} \mathrm{TS} 1} /\left(\pi d_{\mathrm{eq}} \eta_{\mathrm{A}} \Delta Z\right)
\end{gathered}
$$

A deviation within $\pm 1 \mathrm{~kW} \mathrm{~m}^{-2}$ of the targeted average heat flux was allowed to adjust for the test conditions, except for the dryout condition during the evaporation. For the dryout condition, the deviation from $-4 \mathrm{~kW}$ $\mathrm{m}^{-2}$ to $+1 \mathrm{~kW} \mathrm{~m}^{-2}$ was tolerated. The condensation and evaporation tests were carried out at the saturation temperatures, which are the average of the bubble and dew temperatures, 40 and $10{ }^{\circ} \mathrm{C}$, respectively.

Table 2 compares the thermophysical properties between the test refrigerants at average saturation temperatures of 40 and $10{ }^{\circ} \mathrm{C}$ calculated with REFPROP 9.1 (Lemmon et al., 2013). The mixing parameters for the combination of R32 and R1234ze(E) have been optimized by Akasaka et al. (2013) to fit the P $\rho T$ properties measured by Kobayashi et al. (2013). The following two indices, the bias, $\bar{\varepsilon}$, and the standard deviation, $\sigma$, will be used to compare the predicted values. 


$$
\begin{aligned}
\bar{\varepsilon}=\frac{1}{n} \sum_{j=1}^{n} \varepsilon_{j}=\frac{1}{n} \sum_{j=1}^{n}\left[\left(\alpha_{\mathrm{cal}, j}-\alpha_{\mathrm{exp}, j}\right) / \alpha_{\mathrm{exp}, j}\right] \text { or } & =\frac{1}{n} \sum_{j=1}^{n}\left[\left(\Delta P / \Delta \mathrm{Z}_{\mathrm{cal}, j}-\Delta P / \Delta Z_{\text {exp }, j}\right) /\left(\Delta P / \Delta Z_{\text {exp }, j}\right)\right] \\
\sigma & =\sqrt{\frac{1}{n-1} \sum_{j=1}^{n}\left(\varepsilon_{j}-\bar{\varepsilon}\right)^{2}}
\end{aligned}
$$

where $n$ is the number of data points to be compared. The subscripts "cal" and "exp" indicate the prediction and the experiment.

\section{Results and discussion}

\section{Effects of Mass Fraction on HTC and Pressure Gradients for the Binary Mixture (Identification of Mass Transfer Resistance)}

Figure 3 summarizes the results of HTC on the binary mixture R32/R1234ze(E) to identify the effects of the volatility difference in the heat transfer, which is typically called the "mass transfer resistance" (Jung and Radermacher, 1993). Figures 3 (a) and 3 (b) plot the HTC of the binary mixture at a mass flux of 200 $\mathrm{kg} \mathrm{m}^{-2} \mathrm{~s}^{-1}$ and a heat flux of $10 \mathrm{~kW} \mathrm{~m}{ }^{-2}$ as the function of the circulation composition of $\mathrm{R} 32$ in the lower graphs for condensation flow at $40{ }^{\circ} \mathrm{C}$ and evaporation flow at $10{ }^{\circ} \mathrm{C}$, respectively. The plotted symbols are interpolated HTC from the experimental data at fixed vapor qualities 0.7 and 0.5 for condensation and 0.2 , 0.5 , and 0.8 for evaporation. The thin lines are the ideal HTC that is predicted by the correlation proposed for single components in the consideration of change in the thermophysical and transfer properties. The correlations of Yonemoto-Koyama (2007) were selected for the ideal condensation of HTC; the correlation of Kondou et al. (2013) was selected for the ideal evaporation of HTC. As shown in the lower graphs of Figure 3, the HTC of the binary mixture is severely decreased from the ideal HTC. The severe decrease in HTC is caused by the volatility difference and is more evident for evaporation heat transfer.

To briefly describe the mechanism of mass transfer resistance, the volatility difference affects the heat transfer in two ways. One is the additionally required sensible heat transfer. As the condensation proceeds, for instance, the liquid flow condensed at the higher temperature upstream has to be cooled to the local saturation temperature downstream to maintain thermal equilibrium. The other is the concentration distribution induced by the mass transfer. During the condensation, the less volatile component R1234ze(E) 
readily condenses, while the more volatile component R32 remains in the vapor phase. Consequently, the concentration boundary layer is formed near the liquid-vapor interface and locally decreases the saturation temperature, which decreases the effective subcooling between the interface and the tube wall.

As shown in Figure 3 (a), the experimentally determined condensation HTC is decreased most at the circulation composition of approximately 0.45 . The predicted HTC shown with the thick line is calculated by the correlation of Koyama et al. (1999) and is minimized at the composition of approximately 0.3 for the vapor quality 0.7 . The upper graph of Figure 3 (a) shows the temperature glide with the thick line and mutual mass diffusion coefficient in the vapor core, $D_{\mathrm{v}}$, with the thin line calculated by the correlation of Chapman and Enskog (Reid et al., 1987). The mass diffusion coefficient decreases when the composition of $X_{\mathrm{R} 32}$ increases. The decrease in the diffusion coefficient indicates stronger distribution in the concentration and a greater decrease in the local saturation temperature. As a consequence, the methodology of Koyama et al. (1999) exhibits the minimum point of HTC at the composition of 0.3, where it is somewhat shifted to the R32-rich side from the maximum point of temperature glide at the composition of 0.2. The reason why the minimum point of the experimental HTC is further shifted to the R32-rich side is most likely caused by the estimation error in the mass diffusivity and the mass transfer coefficient in the methodology. Nevertheless, that methodology qualitatively represents the effect of the concentration distribution in the vapor core on the condensation heat transfer.

As shown in Figure 3 (b), the experimentally determined condensation HTC is decreased most at circulation compositions of approximately $0.15,0.2$, and 0.3 for the vapor qualities of $0.2,0.5$, and 0.8 , respectively. As shown in the upper graph of Figure 3 (b), these compositions almost correspond to the condition where the mole fraction difference between liquid and vapor, $\left|\tilde{X}_{\mathrm{R} 32}-\tilde{Y}_{\mathrm{R} 32}\right|$, is maximized for each vapor quality. The mole fraction difference represents the strength of the concentration distribution, which induces the local increase in the saturation temperature. The diffusion speed is significantly slower than that in the vapor. Therefore, the concentration distribution is considered to be more significant in liquid than in vapor near the liquid-vapor interface. Furthermore, the similar concentration boundary layer is formed in the superheated sublayer on the boiling site and suppresses the nucleate boiling. This reinforces the two effects mentioned above. That is why the mass transfer resistance is more evident in evaporation flow. 
Figures 4 (a) and 4 (b) show the variation in pressure gradient against the circulation composition for the condensation flow at $40{ }^{\circ} \mathrm{C}$ and evaporation flow at $10{ }^{\circ} \mathrm{C}$, respectively. For both cases, the pressure gradient gradually decreases with increasing composition. This is mainly because the vapor velocity decreases as the vapor density increases when increasing the mass fraction of R32. The dashed and solid lines show the calculated pressure gradient by the correlation proposed for other single components. The calculated pressure gradient agrees well with the experimental pressure gradient. Therefore, considering the property change in the binary mixture, the pressure gradient can be well predicted with the correlation proposed for single components. It appears that the influence of mass transfer resistance is negligible in the momentum transfer. The role of the mass transfer resistance in the heat transfer of the ternary mixture $\mathrm{R} 744 / \mathrm{R} 32 / \mathrm{R} 1234 z e(\mathrm{E})$ is to be stated below with the literature review.

\section{Comparison on Condensation Heat Transfer between Binary and Ternary Mixtures}

Figure 5 shows the variation in the condensation HTC as a function of the vapor quality at an average saturation temperature of $40{ }^{\circ} \mathrm{C}$, a mass flux of $200 \mathrm{~kg} \mathrm{~m}^{-2} \mathrm{~s}^{-1}$ and a heat flux of $10 \mathrm{~kW} \mathrm{~m}^{-2}$. In Figures 5 (a), (b), and 5 (c), the experimental HTC are plotted with symbols for the single components R32 and R1234ze(E) alone, the binary mixture R32/R1234ze(E), and the ternary mixture R744/R32/R1234ze(E), respectively. The horizontal and vertical bars appended to the symbols show the propagated measurement uncertainty of $95 \%$ coverage (Taylor, 1997) in the HTC and the vapor quality change in each subsection. The lines are the predicted HTC according to the correlation of Cavallini et al. (2009) with the correction method of Silver-Bell-Ghaly $(1942,1973)$ for non-azeotropic refrigerant mixtures. Tables 3 and 4 list the comparison results of HTC between the experiment and the correlation's two indices, bias $\bar{\varepsilon}$ and standard deviation $\sigma$.

As shown in Figure 5 (a), the HTC of R32 exceeds that of R1234ze(E), as predicted by the correlation. Other correlations listed in Table 3 also predict the same tendency. The higher liquid thermal conductivity and the larger latent heat of R32 increase the condensation HTC. The correlation proposed for the single components seems to properly include these effects to predict the condensation HTC. Nevertheless, the experimental HTC values deviate at vapor qualities beyond 0.7. According to Kedzierski and Goncalves 
(1999), this deviation is typically evident in the test section of a counter flow configuration, such as the one used in this study. They also tested the parallel flow and remarked that the drastic increases in HTC appear at higher vapor qualities and only with a counter flow configuration.

As shown in Figures 5 (b) and 5 (c), the HTC values of binary and ternary mixtures are significantly lower than those of the single component. This difference typically is the result of the volatility difference. The less volatile components readily condense, while the more volatile components remain in the vapor phase. Therefore, the saturation temperature decreases as condensation proceeds. This phenomenon is dubbed temperature glide and requires additional de-superheating to cool the vapor flow to the local saturation temperature downstream. In addition, a concentration boundary layer forms near the interface between the vapor and liquid, which is associated with the strong temperature distribution. The concentration boundary layer further disturbs smooth condensation, and the temperature distribution near the interface reduces the effective subcooling, which is the driving force of condensation. Therefore, the HTC of zeotropic mixtures decreases from the ideal HTC calculated only with the thermophysical properties of normal condensing flow.

Silver (1942) shed light on the additionally required desuperheating associated with the temperature glide to condense zeotropic mixtures, and Bell and Ghaly (1973) later proposed the correction method to include the sensible heat transfer in the total heat transfer of condensers. Smit et al. (2002) validated this correction method with their experimental data for R22/R142b in horizontal smooth tubes. They demonstrated that the correction method works best with the correlation that Dabson and Chato (1998) proposed for normal condensation. For microfin tubes, the correlation of Cavallini et al. (2009), which shows good agreement for R32 and R1234ze(E), was selected. To improve the fidelity of the actual phenomenon, the local decrease in saturation temperature attributed to the concentration distribution should be considered. For the calculation considering the concentration distribution, a complicated iterative computation is needed according the methodology of Koyama et al. (1999). Because the effects of the concentration distribution are relatively small compared to the effects of temperature glide, the simplification by the method of Silver- Bell- Ghaly was justified.

As shown in Figures 5 (b) and 5 (c), the HTC of R744/R32/R1234ze(E) (9/29/62 mass\%) is somewhat lower than those of the other binary and ternary mixtures. Among the thermophysical properties, only the 
temperature glide significantly differs, as listed in Table 2. The larger temperature glide of R744/R32/R1234ze(E) (9/29/62 mass\%) requires more sensible heat transfer and reduces the effective subcooling to a greater extent. As a result, the HTC of R744/R32/R1234ze(E) (9/29/62 mass\%) is lower than that of the other ternary mixture.

Figures 6 (a) and (b) plot the HTC of ternary mixtures at mass velocities from 150 to $400 \mathrm{~kg} \mathrm{~m}^{-2} \mathrm{~s}^{-1}$. The HTC values of these mixtures markedly increase as the mass flux increases. The rate of this increase in the HTC is more significant than that of the single component. At mass velocities of $400 \mathrm{~kg} \mathrm{~m}^{-2} \mathrm{~s}^{-1} \mathrm{and}^{\mathrm{N}}$ beyond, the HTC seems to revert to values similar to those of the single components. The predictions obtained using the Silver-Bell-Ghaly correction method apparently agree well with the experimental data at a mass flux of $200 \mathrm{~kg} \mathrm{~m}^{-2} \mathrm{~s}^{-1}$, as shown in Figure 5; however, the experimental HTC deviates from the predicted HTC, especially at mass velocities above $300 \mathrm{~kg} \mathrm{~m}^{-2} \mathrm{~s}^{-1}$.

Figure 6 (c) plots the variation in HTC of R744/R32/R1234ze(E) (9/29/62 mass\%) as a function of the mass flux. The symbols are the experimental HTC extracted from the data over the vapor quality range from 0.4 to 0.6 . The solid line is the predicted HTC calculated using the correlation of Cavallini et al. (2009) associated with Silver-Bell-Ghaly (1942, 1973). The dashed line is the ideal HTC that is calculated using the correlation of Cavallini et al. (2009) alone while simply considering the effects of thermophysical properties in "normal" condensation. The experimental HTC of the ternary mixture approaches that of the ideal HTC as the mass flux increases. This finding suggests that increasing the mass flux mitigates the mass transfer resistance caused by the volatility difference. Smit and Meyer (2002) experimentally confirmed a similar effect. The mass fraction of refrigerant mixture R22/R142b influences the average HTC at vapor qualities ranging from 0.1 to 0.85 and mass velocities between 40 and $350 \mathrm{~kg} \mathrm{~m}^{-2} \mathrm{~s}^{-1}$; on the contrary, it does not influence the HTC at mass velocities beyond $350 \mathrm{~kg} \mathrm{~m}^{-2} \mathrm{~s}^{-1}$. Although the critical mass flux at which the influence of the mass transfer resistance vanishes is different, these two results are qualitatively identical. The concentration boundary layer is most likely thinned and partly broken at higher refrigerant flow speeds, and the critical mass flux should depend on the magnitude of the volatility difference. 


\section{Comparison of Evaporation Heat Transfer between Binary and Ternary Mixtures}

Figures 7 (a), 7 (b), and 7 (c) plot the evaporation HTC of the single components R32 and R1234ze(E) alone, the binary mixtures R32/R1234ze(E), and the ternary mixtures R744/R32/R1234ze(E), respectively, at an average saturation temperature of $10^{\circ} \mathrm{C}$, a mass flux of $200 \mathrm{~kg} \mathrm{~m}^{-2} \mathrm{~s}^{-1}$, and a heat flux of $10 \mathrm{~kW} \mathrm{~m}$. The lines are the predicted HTC calculated by the correlation of Mori et al. (2002) for single components and of Cavallini et al. (1998) for the binary and ternary mixtures. The onset and completion dryout qualities and post-dryout HTC are predicted by the correlation of Yoshida et al. (2000) and Mori et al. (2000).

Compared in Figure 7 (a), the HTC of R32 markedly exceeds that of R1234ze(E). This finding is primarily attributed to the higher liquid thermal conductivity and the larger latent heat of R32, as listed in Table 2. The surface tension of R32 is smaller than that of R1234ze(E) at a given saturation temperature, and this difference reduces the bubble departure diameter and increases the bubble departure frequency. Thus, this effect enhances the nucleate boiling contribution at lower vapor qualities of approximately less than 0.4. Table 5 lists the deviations of the predicted HTC from the experimental HTC, i.e., $\bar{\varepsilon}$ and $\sigma$. These deviations are acceptably small, except for that of the correlation proposed by Chamra and Mago (2007), and these correlations accurately predict the evaporation HTC for both of the single components R1234ze(E) and R32.

As plotted in Figures 7 (b) and 7 (c), the evaporation HTC values of the binary and ternary mixtures are drastically lower than those of the single components. This behavior is typical of zeotropic mixtures. The evaporation process enriches the liquid phase in the less volatile components due to this volatility difference, while the vapor phase becomes richer in the more volatile components. Thus, a concentration boundary forms over the liquid-vapor interface and in the superheated sublayer of the nucleate boiling site adjacent to the tube wall (Thome, 1983). Therefore, the saturation temperature is locally increased in the rich concentration boundary layer of the less volatile component. This increase requires more heating to yield nucleate boiling on the tube wall and to evaporate the liquid-vapor interface. Moreover, additional heat is required to heat the vapor flow to the local saturation temperature because of the temperature glide, as mentioned by Butterworth (1981) and Stephan (1992). Therefore, heat transfer degradation is distinct in the evaporation HTC of the zeotropic mixtures for the entire range of vapor quality. Table 6 lists the 
deviation between the predicted HTC and the experimental HTC. Despite the complicating mechanism of the volatility difference, the selected correlations satisfactorily agree with the experimental HTC, except for the correlation proposed by Murata (1996) for binary mixtures. A comparison of the HTC between mixtures shows that the HTC of R744/R32/R1234ze(E) (9/29/62 mass\%), which showed the largest temperature glide, is slightly lower and begins dryout at a slightly lower vapor quality than the other mixtures. The correlation proposed by Cavallini et al. (1998) qualitatively predicts this difference, as shown in Figures 7 (b) and 7 (c).

Figures 8 (a) and 8 (b) plot the evaporation HTC of R744/R32/R1234ze(E) (4/43/53 mass\%) and (9/29/62 mass\%), respectively, at mass velocities from 150 to $600 \mathrm{~kg} \mathrm{~m}^{-2} \mathrm{~s}^{-1}$. The lines are the predicted HTC calculated using the correlation of Cavallini et al. (1998), as well as that of Yoshida et al. (2000) and Mori et al. (2000), for the dryout region. The correlation of Cavallini et al. (1998) unfortunately overestimates the HTC at lower vapor qualities. If the suppression of nucleate boiling by the volatility difference was more accurately predicted, the correlation would show excellent agreement with the present experimental HTC. The experimental data shows an obvious positive correlation with the mass flux, and the correlation qualitatively predicts this effect.

Figure 8 (c) shows the variation in the evaporation HTC of R744/R32/R1234ze(E) (9/29/62 mass\%) as a function of the mass flux. The symbols are the experimental HTC extracted from the database for vapor qualities ranging from 0.4 to 0.6 . The solid line shows the predicted HTC of zeotropic mixtures calculated using the correlation of Cavallini et al. (1998). The dashed line shows the ideal HTC calculated using the correlation of Cavallini et al. (1998), which only considers the effect of the thermophysical properties and was proposed for single components. The experimental HTC approaches the ideal HTC. Increasing the mass flux apparently mitigates the influence of the mass transfer resistance, and the predicted HTC exhibits this effect very well. In contrast to the condensation, the HTC of the mixture remains lower than that of the ideal HTC. The influence of the mass transfer resistance seems to be more severe in evaporation heat transfer. 


\section{Comparison of the Pressure Gradients between Binary and Ternary Mixtures}

Figures 9 (a) and 9 (b) plot the pressure gradients of the ternary mixtures during condensation and evaporation, respectively, at mass velocities of 150 and $400 \mathrm{~kg} \mathrm{~m}^{-2} \mathrm{~s}^{-1}$. The lines are the pressure gradients predicted by the correlation of Yonemoto-Koyama (2007) and Kubota et al. (2001) for condensation and evaporation, respectively. Although these correlations were proposed for single components and not zeotropic mixtures, they accurately predict the pressure gradients of the mixtures. As listed in Table 7, other correlations for the single components also agreed well with the experimental HTC. The influence of the volatility difference on the pressure gradient is seemingly negligible. Therefore, the pressure gradients of these two mixtures of similar thermophysical properties are comparable, despite the difference in the temperature glide. The pressure gradient during the evaporation is considerably larger than that of the condensation because the vapor density is smaller at reduced pressures, i.e., lower saturation temperatures.

\section{Conclusion}

The heat transfer coefficients and pressure gradients of the binary mixtures R32/R1234ze(E) and the ternary mixtures R744/R32/R1234ze(E) with a GWP of approximately 200 and 300 in horizontal microfin tubes have been experimentally investigated in this study. The condensation HTC of R32 alone is somewhat higher than that of R1234ze(E) due to superior thermophysical properties, as predicted by the correlations. However, the HTC values of the binary and ternary mixtures are drastically lower than those of the single components. The HTC was severely decreased due to the mass transfer resistance. This severe influence of the mass transfer resistance was quantified: the influence is obviously mitigated by increasing the mass flux. At mass velocities exceeding $400 \mathrm{~kg} \mathrm{~m}^{-2} \mathrm{~s}^{-1}$, the HTC of the mixture approaches that of the single component. The correction method proposed by Silver-Bell-Ghaly $(1942,1973)$ predicts the influence of the mass transfer resistance in general; however, this correction underestimates the HTC at higher velocities, where the mass transfer resistance is fully mitigated. Similar to the condensation HTC, the evaporation HTC of R32 alone is higher than that of the R1234ze(E) alone. The evaporation HTC values of the binary and ternary mixtures were also drastically lower than those of the single components due to the mass transfer resistance caused by the volatility difference. The mass transfer resistance 
suppresses the nucleate boiling contribution and the forced convective contribution. Therefore, the decrease in the HTC is more severe for the evaporation than the condensation. Despite the complicating mechanism of the mass transfer resistance, the experimental HTC and predicted HTC by Cavallini et al. (1998) showed satisfactory agreement. The correlation proposed for single components for the condensation and the evaporation accurately predicted the pressure gradients of the mixtures. The influence of the volatility difference on the pressure gradient is negligible.

\section{Acknowledgements}

The work presented here was financially supported by the New Energy and Industrial Technology Development Organization (NEDO). The test microfin tube was kindly provided by Kobelco and Materials Copper Tube, Ltd.

\section{Nomenclature}

$\begin{array}{lll}C p & \text { isobaric specific heat } & \left(\mathrm{J} \mathrm{kg}^{-1} \mathrm{~K}^{-1}\right) \\ D_{\mathrm{o}} & \text { outer diameter } & (\mathrm{m}) \\ G_{\mathrm{r}} & \text { mass flux } & \left(\mathrm{kg} \mathrm{m}^{-2} \mathrm{~s}^{-1}\right) \\ P & \text { pressure } & (\mathrm{Pa}) \\ \Delta P & \text { differencial pressure } & (\mathrm{Pa}) \\ Q & \text { heat transfer rate } & (\mathrm{W}) \\ Q_{\text {loss }} & \text { heat loss } & (\mathrm{W}) \\ T & \text { temperature } & \left({ }^{\circ} \mathrm{C}\right) \\ U & \text { uncertunty } & (-) \\ V & \text { volumetric flow rate } & \left(\mathrm{m}^{3} \mathrm{~s}^{-1}\right) \\ W & \text { mass flow rate } & \left(\mathrm{kg} \mathrm{s}^{-1}\right) \\ X & \text { mass fraction } & (-) \\ Z & \text { tube length } & (\mathrm{m})\end{array}$




$\begin{array}{lll}\Delta Z_{\mathrm{DP}} & \text { interval of pressure ports } & (\mathrm{m}) \\ \Delta Z \alpha & \text { active heat transfer length }(\mathrm{m}) \\ d_{\mathrm{eq}} & \text { equivalent inner diameter } & (\mathrm{m}) \\ h & \text { specific enthalpy } & \left(\mathrm{J} \mathrm{kg}^{-1}\right) \\ n & \text { number of data points } & (-) \\ q & \text { heat flux } & \left(\mathrm{W} \mathrm{m} \mathrm{m}^{-2}\right) \\ x & \text { vapor quality } & (-) \\ \alpha & \text { heat transfer coefficient } & \left(\mathrm{W} \mathrm{m} \mathrm{K}^{-1}\right) \\ \varepsilon & \text { bias } & (-) \\ \eta_{\mathrm{A}} & \text { surface enlargement } & (-) \\ \lambda & \text { thermal conductivity } & \left(\mathrm{W} \mathrm{m} \mathrm{K}^{-1}\right) \\ & \text { standard deviation } & \left(\mathrm{kg} \mathrm{m}^{-3}\right) \\ & & \end{array}$

\section{Subscripts}

$\begin{array}{ll}\text { bub } & \text { bubble point } \\ \text { bottom } & \text { bottom } \\ \text { dew } & \text { calculation } \\ \text { DH } & \text { dew point } \\ \text { exp } & \text { experiment } \\ \text { H2O } & \text { water } \\ \text { i } & \text { inlet } \\ \text { left } & \text { left } \\ \text { max } & \text { maximum } \\ \text { min } & \text { minimum } \\ \text { o } & \text { outlet }\end{array}$




$\begin{array}{ll}\text { r } & \text { refirigerant } \\ \text { R32 } & \text { R32 } \\ \text { R744 } & \text { R744 } \\ \text { right } & \text { right } \\ \text { TS } & \text { test section } \\ \text { top } & \text { top } \\ \text { tube } & \text { tube } \\ \text { wi } & \text { inner wall } \\ \text { wo } & \text { outer wall } \\ \text { wo } & \text { outer wall } \\ 1 \sim 4 & \text { position of the subsection }\end{array}$




\section{Appendix A}

\section{Uncertainty Analysis}

Figure A.1 illustrates the data reduction procedure for the condensation test. Following Figure A.1, the calculation procedure of the uncertainties are hereinafter stated in detail for the condensation test using the ternary mixture R744/R32/R1234ze(E). The procedures for the evaporation test and the single components or the binary mixture are essentially the same. The $95 \%$ coverage of the uncertainty propagated with several variables is obtained by means of the square-root rule (Taylor 1982; Moffat, 1988), assuming that the variables are independent and random.

\section{Uncertainty in Local Pressure and Pressure Drop}

The uncertainties in local pressures, from $P_{0}$ to $P_{5}$, are given as the combination of uncertainties in the absolute pressure $P_{\mathrm{TSi}}$ and the differential pressures $\Delta P_{01}$ to $\Delta P_{05}$.

$$
\begin{gathered}
U_{P_{1}}{ }^{2}=U_{P_{\mathrm{TSi}}}{ }^{2}+U_{\Delta P_{01}{ }^{2}}{ }^{2}{ }_{P_{2}}{ }^{2}=U_{P_{0}}{ }^{2}+U_{\Delta P_{02}{ }^{2}} \\
\vdots \\
U_{P_{5}}{ }^{2}=U_{P_{0}}{ }^{2}+U_{\Delta P_{05}}{ }^{2}
\end{gathered}
$$

The uncertainties in the pressure drop $U_{\Delta P / \Delta Z}$ of each subsection are obtained as,

$$
\begin{gathered}
U_{(\Delta P / \Delta Z)_{1}}^{2} \approx\left(\frac{U_{\Delta P_{02}}}{\Delta Z_{\mathrm{DP}, 1}}\right)^{2}+\left(-\frac{U_{\Delta P_{01}}}{\Delta Z_{\mathrm{DP}, 1}}\right)^{2}+\left[\left(\frac{\Delta P_{02}-\Delta P_{01}}{\Delta Z_{\mathrm{DP}, 1}^{2}}\right) U_{\Delta Z_{\mathrm{DP}, 1}}\right]^{2} \\
\vdots \\
U_{(\Delta \mathrm{P} / \Delta Z)_{4}}^{2} \approx\left(\frac{U_{\Delta P_{00}}}{\Delta Z_{\mathrm{DP}, 4}}\right)^{2}+\left(-\frac{U_{\Delta P_{04}}}{\Delta Z_{\mathrm{DP}, 4}}\right)^{2}+\left[\left(\frac{\Delta P_{00}-\Delta P_{04}}{\Delta Z_{\mathrm{DP}, 4}^{2}}\right) U_{\Delta Z_{\mathrm{DP}, 4}}\right]^{2}
\end{gathered}
$$

where $U_{\Delta P_{00}} \ldots U_{\Delta P_{00}}$ are the measurement uncertainties arisen with the differential pressure transducer, 0.3 $\mathrm{kPa} . U_{\Delta Z_{\mathrm{DP}, 1}} \ldots U_{\Delta Z_{\mathrm{DP}, 4}}$ are the uncertainties in the intervals of the pressure ports, $0.005 \mathrm{~m}$. Typically, when the pressure drop is $20 \mathrm{kPa} \mathrm{m}^{-1}$, the propagated uncertainty in the pressure drop $(\Delta \mathrm{P} / \Delta \mathrm{Z})$ is $\pm 0.78 \mathrm{kPa} \mathrm{m}^{-1}$, which is approximately $4 \%$ of the obtained value. 


\section{Uncertainties in Heat Flux}

The heat transfer rates in the desuperheater and the subsections are obtained as,

$$
Q_{\mathrm{H} 2 \mathrm{O}}=\rho_{\mathrm{H} 2 \mathrm{O}} C p_{\mathrm{H} 2 \mathrm{O}} V_{\mathrm{H} 2 \mathrm{O}}\left(T_{\mathrm{H} 2 \mathrm{O}, \mathrm{o}}-T_{\mathrm{H} 2 \mathrm{O}, \mathrm{i}}\right)-Q_{\mathrm{loss}}
$$

The uncertainty of water properties is considered negligible compared to that of the other measured parameters. Hence, the uncertainty of the heat transfer rates $U_{Q_{\mathrm{H} 20}}$ in the desuperheater and the subsections are determined by the following formula.

$$
U_{\mathrm{Q}_{\mathrm{H} 2 \mathrm{O}}}{ }^{2} \approx\left[\rho_{\mathrm{H} 2 \mathrm{O}} C p_{\mathrm{H} 2 \mathrm{O}}\left(T_{\mathrm{H} 2 \mathrm{O}, \mathrm{O}}-T_{\mathrm{H} 2 \mathrm{O}, \mathrm{i}}\right) \cdot U_{V_{\mathrm{H} 2 \mathrm{O}}}\right]^{2}+\left(V_{\mathrm{H} 2 \mathrm{O}} \rho_{\mathrm{H} 2 \mathrm{O}} C p_{\mathrm{H} 20}\right)^{2}\left(U_{T_{\mathrm{H} 20, \mathrm{i}}}{ }^{2}+U_{T_{\mathrm{H} 20, \mathrm{i}}}{ }^{2}\right)+U_{Q_{\text {loss }}}{ }^{2}
$$

where $U_{V_{\mathrm{H} 20}}$ and $U_{T_{\mathrm{H} 20}}$ are the uncertainties related to the volumetric flow meter and Pt resistance thermometer as listed in Table A.1. $U_{Q_{\text {loss }}}$ is the uncertainty in heat loss correlated to the temperature difference between the ambient air and the cooling water. Thus, the uncertainties in heat flux based on the actual heat transfer area, which is given by Equation (9), is determined as,

$$
U_{q_{\mathrm{acc}}}{ }^{2} \approx\left(\frac{U_{Q_{\mathrm{H} 20}}}{d_{\mathrm{eq}} \pi \eta_{\mathrm{A}} \Delta Z_{\alpha}}\right)^{2}+\left(\frac{Q_{\mathrm{H} 2 \mathrm{O}}}{d_{\mathrm{eq}} \pi \eta_{\mathrm{A}} \Delta Z_{\alpha}}\right)^{2}\left[\left(\frac{U_{d_{\mathrm{eq}}}}{d_{\mathrm{eq}}}\right)^{2}+\left(\frac{U_{\eta_{\mathrm{A}}}}{\eta_{\mathrm{A}}}\right)^{2}+\left(\frac{U_{\Delta Z_{\alpha}}}{\Delta Z_{\alpha}}\right)^{2}\right]
$$

where $U_{\eta_{\mathrm{A}}}$ is the uncertainty in the surface enlargement ratio on the test tube, assumed as 0.05 .

\section{Uncertainties in Representative Refrigerant Temperatures}

The enthalpy changes over the desuperheater and the subsections are given as,

$$
\Delta h=Q_{\mathrm{H} 2 \mathrm{O}} / W_{r}
$$

Hence, the uncertainty in these enthalpy changes $U_{\Delta h}$ in the desuperheater and the subsections are,

$$
U_{\Delta h}^{2} \approx\left(U_{Q_{\mathrm{H} 20}} / W_{\mathrm{r}}\right)^{2}+\left(-U_{W_{\mathrm{r}}} / W_{\mathrm{r}}^{2}\right)^{2}
$$

where $U_{W_{\mathrm{r}}}$ is the uncertainty related to the mass flow meter as listed in Table A.1. With the above enthalpy change $\Delta h$, the local enthalpy can be expressed as, 


$$
\begin{aligned}
& h_{\mathrm{DHi}}=h_{\mathrm{DHi}}\left(P_{\mathrm{DHi}}, T_{\mathrm{DHi}}, X_{\mathrm{R} 744}, X_{\mathrm{R} 32}\right)_{\text {equilibrium }} \\
& h_{1}=h_{\mathrm{DHi}}-\Delta h_{\mathrm{DH}} \\
& h_{2}=h_{\mathrm{DHi}}-\Delta h_{\mathrm{DH}}-\Delta h_{1} \\
& \vdots \\
& h_{5}=h_{\mathrm{DHi}}-\Delta h_{\mathrm{DH}}-\Delta h_{1}-\Delta h_{2}-\Delta h_{3}-\Delta h_{4}
\end{aligned}
$$

Because the mixing parameters for the mixture are optimized based on the measured $P v T$, the calculation is considered highly accurate. The uncertainty in the enthalpy at the inlet of the desuperheater $h_{\mathrm{DHi}}$ can be calculated as the deviation between the maximum and the minimum enthalpies referring to the 4 measured parameters.

$$
\begin{aligned}
& U_{h_{\mathrm{DHi}}} \approx\left(h_{\mathrm{DHi} \_ \text {max }}-h_{\mathrm{DHi} \_ \text {min }}\right) / 2 \\
& h_{\mathrm{DHi} \_ \text {max }}=\operatorname{Max}\left[h_{\mathrm{DHi}}\left(P_{\mathrm{DHi}} \pm U_{P_{\mathrm{DHi}}}, T_{\mathrm{r}, \mathrm{DHi}} \pm U_{T_{\mathrm{r}, \mathrm{DHi}}}, X_{\mathrm{R} 744} \pm U_{X_{\mathrm{R} 744}}, X_{\mathrm{R} 32} \pm U_{X_{\mathrm{R} 32}}\right)_{\text {equilibrium }}\right] \\
& h_{\mathrm{DHi} \_ \text {min }}=\operatorname{Min}\left[h_{\mathrm{DHi}}\left(P_{\mathrm{DHi}} \pm U_{P_{\mathrm{DHi}}}, T_{\mathrm{r}, \mathrm{DHi}} \pm U_{T_{\mathrm{r}, \mathrm{DHi}}}, X_{\mathrm{R} 744} \pm U_{X_{\mathrm{R} 744}}, X_{\mathrm{R} 32} \pm U_{X_{\mathrm{R} 32}}\right)_{\text {equilibrium }}\right]
\end{aligned}
$$

where $U_{P_{\mathrm{DHF}}}, U_{T_{\mathrm{r}, \mathrm{DHi}}}$, and $U_{X_{\mathrm{R} 744}}\left(=U_{X_{\mathrm{R} 32}}\right)$ are the uncertainties related to the absolute pressure transducer, $\mathrm{K}$ type thermocouples, and the gas-chromatograph, respectively. On the basis of uncertainty $U_{h_{\mathrm{DHI}}}$, the uncertainties in the local enthalpies from $h_{1}$ to $h_{5}$ are propagated as follows.

$$
\begin{aligned}
& U_{h_{1}}{ }^{2}=U_{h_{\mathrm{DHi}}}{ }^{2}+U_{\Delta h_{\mathrm{DH}}}{ }^{2} \\
& U_{h_{2}}{ }^{2}=U_{h_{\mathrm{DHi}}}{ }^{2}+U_{\Delta h_{\mathrm{DH}}}{ }^{2}+U_{\Delta h_{1}}{ }^{2} \\
& \vdots \\
& U_{h_{5}}{ }^{2}=U_{h_{\mathrm{DHi}}}{ }^{2}+U_{\Delta h_{\mathrm{DH}}}{ }^{2}+U_{\Delta h_{1}}{ }^{2}+U_{\Delta h_{2}}{ }^{2}+U_{\Delta h_{3}}{ }^{2}+U_{\Delta h_{4}}{ }^{2}
\end{aligned}
$$

As described in Equation (2), the arithmetic mean of the inlet and outlet temperatures represents the refrigerant temperature in a subsection. Thus, the uncertainty in the representative refrigerant temperature is given as the combination of the uncertainties in the inlet and outlet refrigerant temperatures. For instance, in subsection 1, the uncertainty in the representative refrigerant temperature, $T_{\mathrm{r} 1}$, is,

$$
U_{T_{\mathrm{r} 1}}^{2} \approx\left(U_{T_{\mathrm{r} 1, i}}^{2}+U_{T_{\mathrm{r} 1,0}}^{2}\right) / 2
$$

The uncertainties in inlet and outlet refrigerant temperatures can be calculated with reference to the 4 measured variables. For instance, the uncertainty in the temperature at the inlet of subsection $1, T_{\mathrm{r} 1 \mathrm{i}}$, is, 


$$
\begin{aligned}
& U_{T_{\mathrm{r} 1 \mathrm{i}}} \approx\left(T_{\mathrm{r} 1, \mathrm{i} \_ \text {max }}-T_{\mathrm{r} 1, \mathrm{i} \_ \text {min }}\right) / 2 \\
& T_{\mathrm{r} 1, \mathrm{i} \_ \text {max }}=\operatorname{Max}\left[T_{\mathrm{r} 1, \mathrm{i}}\left(P_{1} \pm U_{P_{1}}, h_{1} \pm U_{h_{1}}, X_{\mathrm{R} 744} \pm U_{X_{\mathrm{R} 744}}, X_{\mathrm{R} 32} \pm U_{X_{\mathrm{R} 32}}\right)_{\text {equilibrium }}\right] \\
& T_{\mathrm{r} 1, \mathrm{i} \text { mmin }}=\operatorname{Min}\left[T_{\mathrm{r} 1, \mathrm{i}}\left(P_{1} \pm U_{P_{1}}, h_{1} \pm U_{h_{1}}, X_{\mathrm{R} 744} \pm U_{X_{\mathrm{R} 74}}, X_{\mathrm{R} 32} \pm U_{X_{\mathrm{R} 32}}\right)_{\text {equilibrium }}\right]
\end{aligned}
$$

\section{Uncertainties in the Tube Wall Temperature}

The interior tube wall temperature $T_{\mathrm{wi}}$ is given by Equation (1). The uncertainty in the interior tube wall temperature, $T_{\mathrm{wi}}$, is obtained as,

$$
\begin{aligned}
U_{T_{\mathrm{wi}}}{ }^{2} \approx & \frac{\left(U_{T_{\mathrm{wo}, \text { top }}}{ }^{2}+U_{T_{\mathrm{wo}, \text { botom }}}{ }^{2}+U_{T_{\mathrm{wo}, \text { reght }}}{ }^{2}+U_{T_{\mathrm{wo}, \text { left }}}{ }^{2}\right)}{4}+\left(\frac{Q_{\mathrm{H} 2 \mathrm{O}}}{2 \pi \lambda_{\text {tube }} \Delta Z_{\alpha}}\right)^{2}\left[\left(\frac{U_{D_{\mathrm{o}}}}{D_{\mathrm{o}}}\right)^{2}+\left(\frac{U_{d_{\mathrm{eq}}}}{d_{\mathrm{eq}}}\right)^{2}\right] \\
& +\left[\ln \left(\frac{D_{\mathrm{o}}}{d_{\mathrm{eq}}}\right)\right]^{2}\left[\left(\frac{U_{Q_{\mathrm{H} 22}}}{2 \pi \lambda_{\text {tube }} \Delta Z_{\alpha}}\right)^{2}+\left(\frac{-Q_{\mathrm{H} 2 \mathrm{O}}}{2 \pi \lambda_{\text {tube }}{ }^{2} \Delta Z_{\alpha}} U_{\lambda_{\text {tube }}}\right)^{2}+\left(\frac{-Q_{\mathrm{H} 2 \mathrm{O}}}{2 \pi \lambda_{\text {tube }} \Delta Z_{\alpha}{ }^{2}} U_{\Delta Z_{\alpha}}\right)^{2}\right]
\end{aligned}
$$

where $U_{T_{\mathrm{wo}, \text { top }}}, U_{T_{\mathrm{wo}, \text { botom }}}, U_{T_{\mathrm{wo}, \text { reght }}}$, and $U_{T_{\mathrm{wo}, \text { left }}}$ are the uncertainties in the exterior tube wall temperatures related to the T type thermocouples as listed in Table A.1. $U_{D_{o}}, U_{d_{\mathrm{eq}}}$, and $U_{\Delta Z_{\alpha}}$ are the uncertainties in the outer diameter, the equivalent inner diameter, and the active heat transfer length of the test tube. Here, those uncertainties $U_{D_{o}}, U_{d_{\mathrm{eq}}}$, and $U_{\Delta Z_{\alpha}}$ were estimated as $0.05 \mathrm{~mm}, 0.25 \mathrm{~mm}$, and $5 \mathrm{~mm}$, respectively.

\section{Uncertainties in HTC}

The propagated uncertainty in average HTC, which is calculated by Equation (8), is obtained as,

$$
U_{\alpha}{ }^{2} \approx\left(\frac{U_{q_{\mathrm{act}}}}{T_{\mathrm{wi}}-T_{\mathrm{r}}}\right)^{2}+\left[\frac{-U_{T_{\mathrm{wi}}}}{\left(T_{\mathrm{wi}}-T_{\mathrm{r}}\right)^{2}}\right]^{2}+\left[\frac{-U_{T_{\mathrm{r}}}}{\left(T_{\mathrm{wi}}-T_{\mathrm{r}}\right)^{2}}\right]^{2}
$$

The uncertainty $U_{\alpha}$ predominantly depends on the temperature difference between tube wall and refrigerant $\left(T_{\mathrm{wi}}-T_{\mathrm{r}}\right)$. 


\section{References}

Akasaka, R., 2013, Thermodynamic Property Models for the Difluoromethane (R-32) + Trans-1,3,3,3tetrafluoro propene (R-1234ze(E)) and Difluoromethane + 2,3,3,3- Tetrafluoropropene (R-1234yf) Mixtures, Fluid Phase Equilibria, vol. 358: p. 98-104.

Bell, K.J., Ghaly, M.A., 1973, An approximate generalized design method for multicomponent/partial condenser AIChE Symp. Ser., vol. 69: p.72-79.

Butterworth, D., 1981, Unsolved problems in heat exchanger design, Heat Exchangers: Thermal-Hydraulic Fundamentals and Design. Edited by Kakac, S., Bergles, A. E., Mayinger. F., Hemisphere, Washington, p. 1093-1096.

Cavallini, A., DelCol, D., Doretti, L., Longo, G.A., Rossetto, L.,1997, Pressure drop during condensation and vaporisation of refrigerants inside enhanced tubes, Int. J. Heat \& Technology, vol. 15: p.3-10.

Cavallini, A., DelCol, D., Mancin, S., Rossetto, L., 2009, Condensation of pure and near-azeotropic refrigerants in microfin tubes: A new computational procedure, Int. J. Refrig., vol. 32: p. 162-174.

Cavalllini, A., DelCol, D., Longo, G.A., Rosset, L., 1998, Refrigerant vaporization inside enhanced tubes, Proc. Heat Transfer in Condensation and Evaporation, Eurotherm seminar, Grenoble, France: p. 222231.

Chamra, L.M., Mago, P.J., 2006, Modeling of condensation heat transfer of refrigerant mixture in micro-fin tubes, Int. J. Heat and Mass Transfer., vol. 49: p. 1915-1921.

Chamra, L.M., Mago, P.J., 2007, Modelling of evaporation heat transfer of pure refrigerants and refrigerant mixtures in microfin tubes. Proc. IMechE., 221, Part C: J. Mechanical Engineering Science: p. 443454.

Chamra, L.M., Mago, P.J., Tan, M.O., Kung, C.C., 2005, Modeling of condensation heat transfer of pure refrigerants in micro-fin tubes, Int. J. Heat and Mass Transfer. vol. 48: p. 1293-1302.

Dobson, M.K., Chato, J.C., 1998, Condensation in Smooth Horizontal Tubes, J. Heat Transfer, Trans. ASME, vol. 120: p. 193-213

Filho, E.P.B., Jabardo, J.M.S., Barbieri, P.E.L., 2004, Convective boiling pressure drop of refrigerant R134a in horizontal smooth and microfin tubes, Int. J. Refrig., vol. 27: p. 895-903.

Fukuda, S., Kondou, C., Takata, N., Koyama, S., 2014, Cycle performance of low GWP refrigerant mixtures R-32/1234ze(E) and R-744/32/1234ze(E), Proc. 7th Asian Conference on Refrigeration and Air Conditioning, paper no. ACRA2014-421.

Goto, M., Inoue, N., Ishiwatari, N., 2001, Condensation and evaporation heat transfer of R410A inside internally grooved horizontal tubes, Int. J. Refrig., vol. 24: p. 628-638.

Goto, M., Inoue, N., Ishiwatari, N., 2007, Answer to comments by M.M. Awad, Int. J. Refrig., vol. 30: p. 1467.

Hossain, M.A., Onaka, Y., Afroz, H.M.M., Miyara, A., 2013, Heat transfer during evaporation of R1234ze(E), R32, R410A and a mixture of R1234ze(E) and R32 inside a horizontal smooth tube, Int. J. Refrig. 36: p. 465-477.

Jakobs, R., Kruse, H., 1978, The use of non-azeotropic refrigerant mixture in heat pumps for energy saving, Proc. IIR Commissions B2: p. 207-218.

Jung, D., Radermacher, R., 1993, Prediction of evaporation heat transfer coefficient and pressure drop of refrigerant mixtures in horizontal tubes, Int. J. Refrig., vol. 16: p. 201-209.

Kedzierski, M.A., Goncalves, J.M., 1999, Horizontal convective condensation of alternative refrigerants within a micro-fin tube, Enhanced Heat Transfer, vol. 6: p. 161-178.

Kobayashi, K., Tanaka, K., Higashi, Y., 2011, P $\rho$ T $\chi$ Property Measurements of Binary HFO1234ze(E)+HFC-32 Refrigerant Mixtures, Trans. JSRAE, vol. 28, no. 4: p. 415-426 (in Japanese).

Kondou, C., BaBa, D., Mishima, F., Koyama, S., 2013, Flow boiling of non-azeotropic mixture R32/R1234ze(E) in horizontal microfin tubes, Int. J. Refrig., 36 (8): p. 2236-2378.

Koyama, S., Higashi, T., Miyara, A., Akasaka, R., 2013, Research and development of low-GWP refrigerants suitable for heat pump systems. In: JSRAE Risk Assessment of Mildly Flammable Refrigerants-2012 Progress Report, JSRAE: p. 29-34. 
Koyama, S., Yu, J., Ishibashi, A., 1999, Heat and mass transfer prediction of binary refrigerant mixtures condensing in a microfin tube, Proc. 5th ASME/JSME Thermal Engineering Join Conf., San Diego, Calofornia, no. AJTE99-6358: p. 1-8.

Kubota, A., Uchida, M., Shikazono, N., 2001, Predicting equations for evaporation pressure drop inside horizontal smooth and grooved tubes, Trans. JSRAE, vol. 18 no. 4: p. 393-401 (in Japanese).

Lemmon, E.W., Huber, M.L., McLinden, M.O., 2013, Reference Fluid Thermodynamic and Transport Properties - REFPROP Ver. 9.1, National Institute of Standards and Technology, Boulder, CO, USA.

McLinden, M.O., Radermacher, R., 1987, Mothod for comparing the performance of pure and mixed refrigerants in the vapour compression cycle, Int. J. Refrig., vol. 10: p. 318-325

Momoki, S., Yu, J., Koyama, S., Fujii, T., Honda, H., 1995, A correlation for forced convective boiling heat transfer of refrigerants in a microfin tube, Trans. JAR, vol. 12, no. 2, p. 177-184 (in Japanese).

Mori, H., Yoshida, S., Kakimoto, Y., Ohishi, K., Fukuda, K., 2000, Post-dryout heat transfer to a refrigerant flowing in horizontal evaporator tubes, Trans. JSRAE, vol. 4: p. 521-528 (in Japanese).

Mori, H., Yoshida, S., Koyama, S., Miyara, A., Momoki, S., 2002, Prediction of heat transfer coefficients for refrigerants flowing in horizontal spirally grooved evaporator tubes, Proc. 14th JSRAE Annual Conf:: p. 97-100 (in Japanese).

Murata, K., 1996, Correlation for forced convective boiling heat transfer of binary refrigerant mixtures 2nd report: a spirally grooved tube, Trans. JSME (B), vol. 62, no. 599: p. 2723-2728 (in Japanese).

Newell, T.A., Shah, R.K., 2001, An assessment of refrigerant heat transfer, pressure drop, and void fraction effects in microfin tubes, HVAC\&R Research, vol. 7, no. 2: p. 125-153.

Niederküger, M., Steiner, D., 1994, Flow boiling heat transfer to saturated pure components and nonazeotropic mixtures in a horizontal tube, Chem. Eng. Prog., vol. 33: p. 261-275.

Reid, R.C, Prausnitz, J.M., Poling, B.E., 1986, The properties of gases and liquids, 4th ed., McGraw-Hill, New York, p. 581-582.

Silver, L., 1942, Gas cooling with aqueous condensation, Trans. Inst. Chem. Eng., vol. 20, no. 14: p. 30-42.

Smit, F.J., Meyer, J.P., 2002, Condensation heat transfer coefficient of the zeotropic refrigerant mixture R22/R142b in smooth horizontal tubes. Int. J. Thermal Science, vol. 41: p. 625-630.

Smit, F.J., Thome, J.R., Meyer, J.P., 2002, Heat transfer coefficients during condensation of the zeotropic refrigerant mixture HCFC-22/HCFC142b, J. Heat Transfer, Trans. ASME, vol. 124: p. 1137-1146.

Stephan, K., 1992, Heat transfer in condensation and boiling, Translated by Green, C.V., Springer-Verlag, Berlin, Heidelberg, p. 286-291.

Taylor, J.T., 1997, An introduction to error analysis, 2nd ed., University science book.

Thome, J.R., Kattan, N., Favrat, D., 1997, Evaporation in microfin tubes: a generalized prediction model, Proc. Convective Flow and Pool Boiling Conf., Kloster Irsee, Germany, Paper VII-4.

Thome, J.R., 1983, Prediction of binary mixture boiling heat transfer coefficients using only phase equilibrium data, Int. J. Heat Mass Transfer, 26 (7), 965-974.

Wang X., Amrane, K., 2014, AHRI low global warming potential alternative refrigerants evaluation program (low-GWP AREP) - summary of phase I testing results, 15th International Refrigeration and Air Conditioning Conference at Purdue, West Lafyette, IN, no. 2250: p. 1-10.

Yonemoto R., Koyama S., 2007, Experimental study on condensation of pure refrigerants in horizontal micro-fin tubes: proposal of correlations for heat transfer coefficient and frictional pressure drop, Trans. JSRAE, vol. 24, no. 2: p. 139-148, (in Japanese).

Yoshida, S., Mori, H., Kakimoto, Y., Ohishi, K., 2000, Dryout quality for refrigerants flowing in horizontal evaporator tubes, Trans. JSRAE, vol. 4, p. 511-520 (in Japanese)

Yun, R., Kim, Y., Seo, K., Kim, H.Y., 2002, A generalized correlation for evaporation heat transfer of refrigerants in micro-fin tube, Int. J. Heat Mass Transfer, vol. 45: p. 2003-2010. 


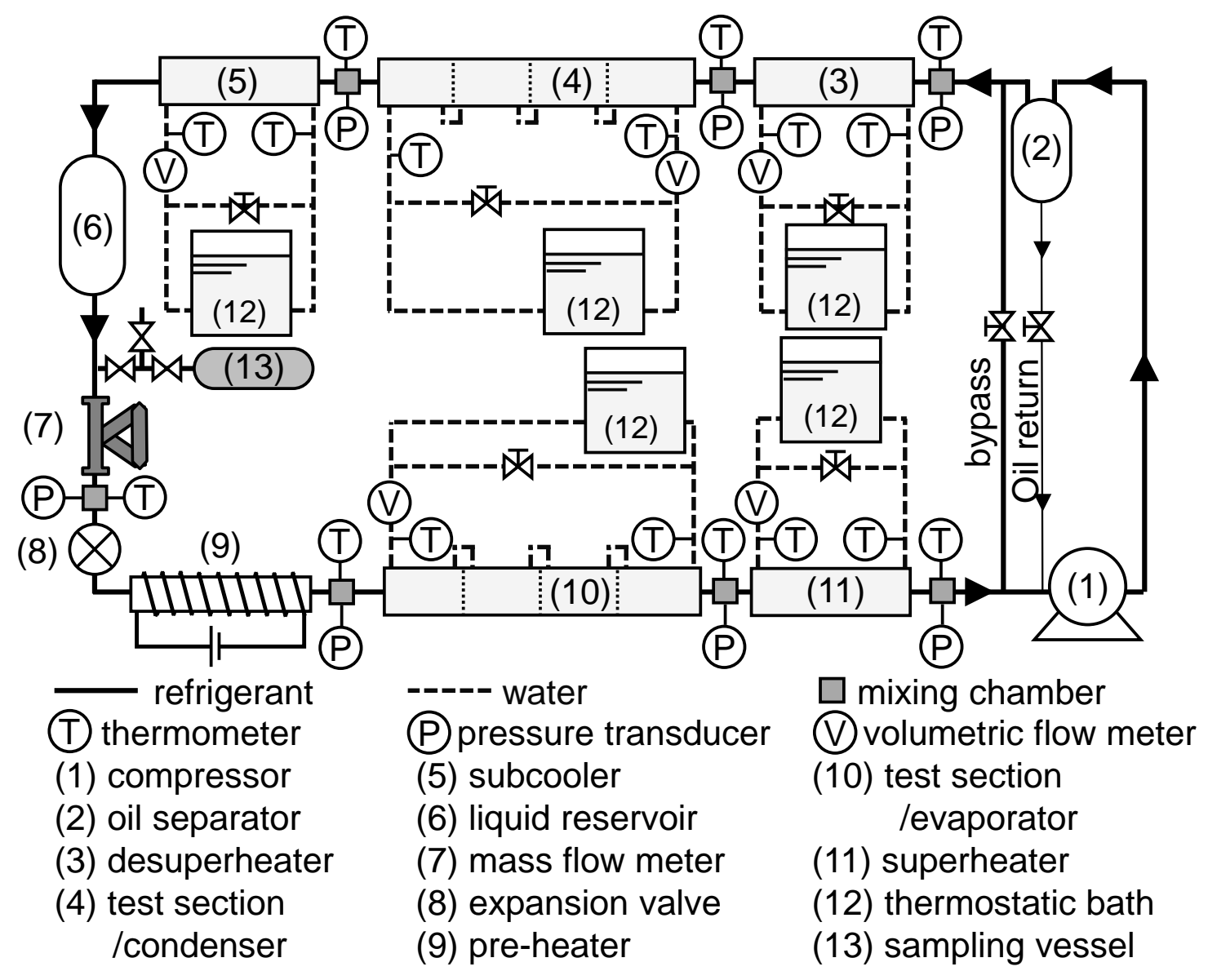

(a) Diagram of the test loop

Figure 1 Experimental apparatus 


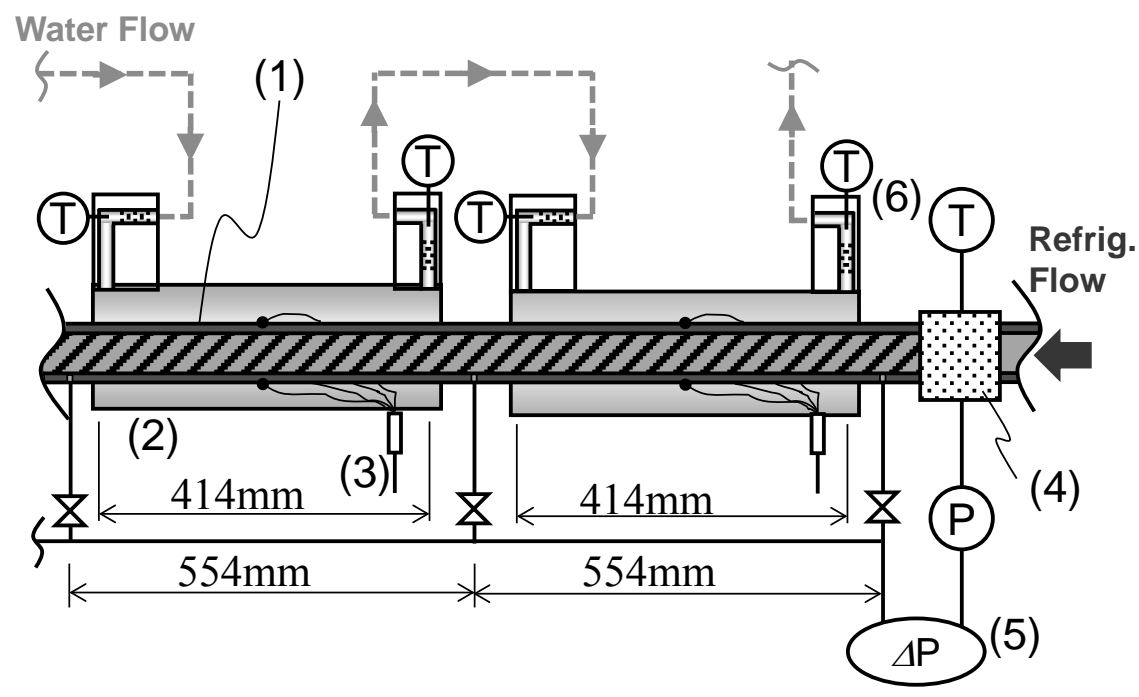

(1) test microfin tube (4) mixing chamber for refrigerant

(2) water jacket

(3) thermocouple

(5) differential pressure transducers

(6) mixing chamber for water

(b) Structure of the test section (for the condensation test)

Figure 1 Experimental apparatus (continued)

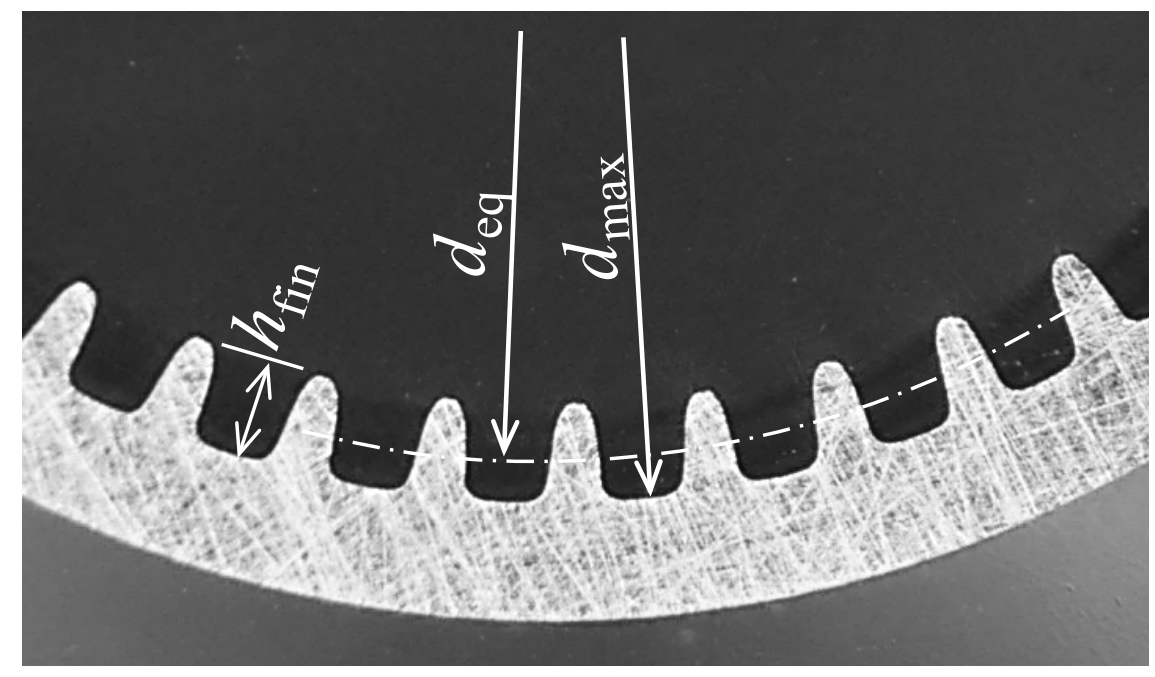

Figure 2 Microscopic cross section of the test microfin tube 


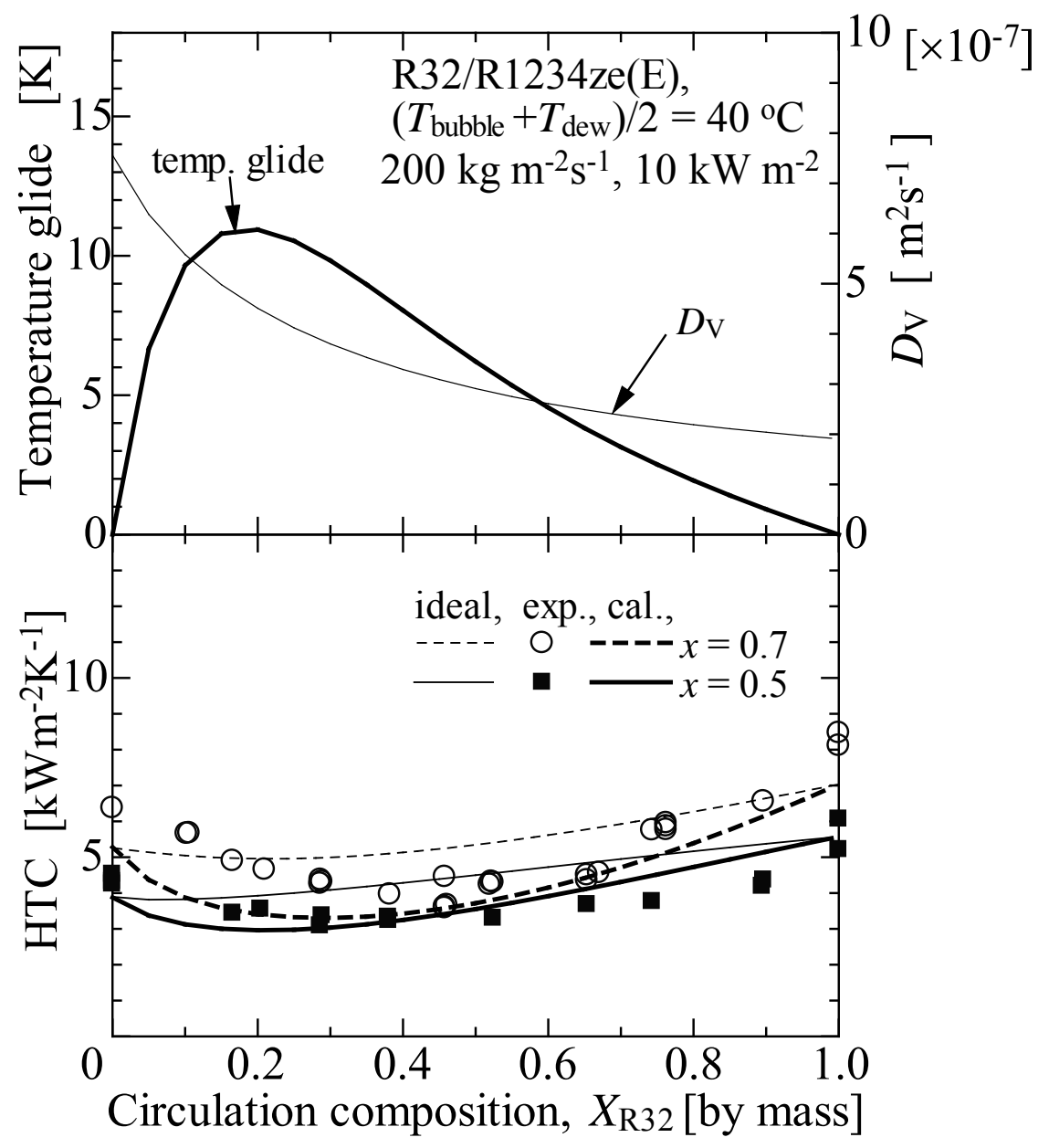

(a) Condensation heat transfer at $40{ }^{\circ} \mathrm{C}$ (a) condensation heat transfer at $40{ }^{\circ} \mathrm{C}$ (The ideal HTC are predicted by correlations of Yonemoto-Koyama (2007), the calculated HTC shown with the thick linew are considering the mass transfer resistance calculated by the methodology of Koyama et al. (1999).

Figure 3 Variation in the HTC of the binary mixture R32/R1234ze(E) against the circulation composition. 


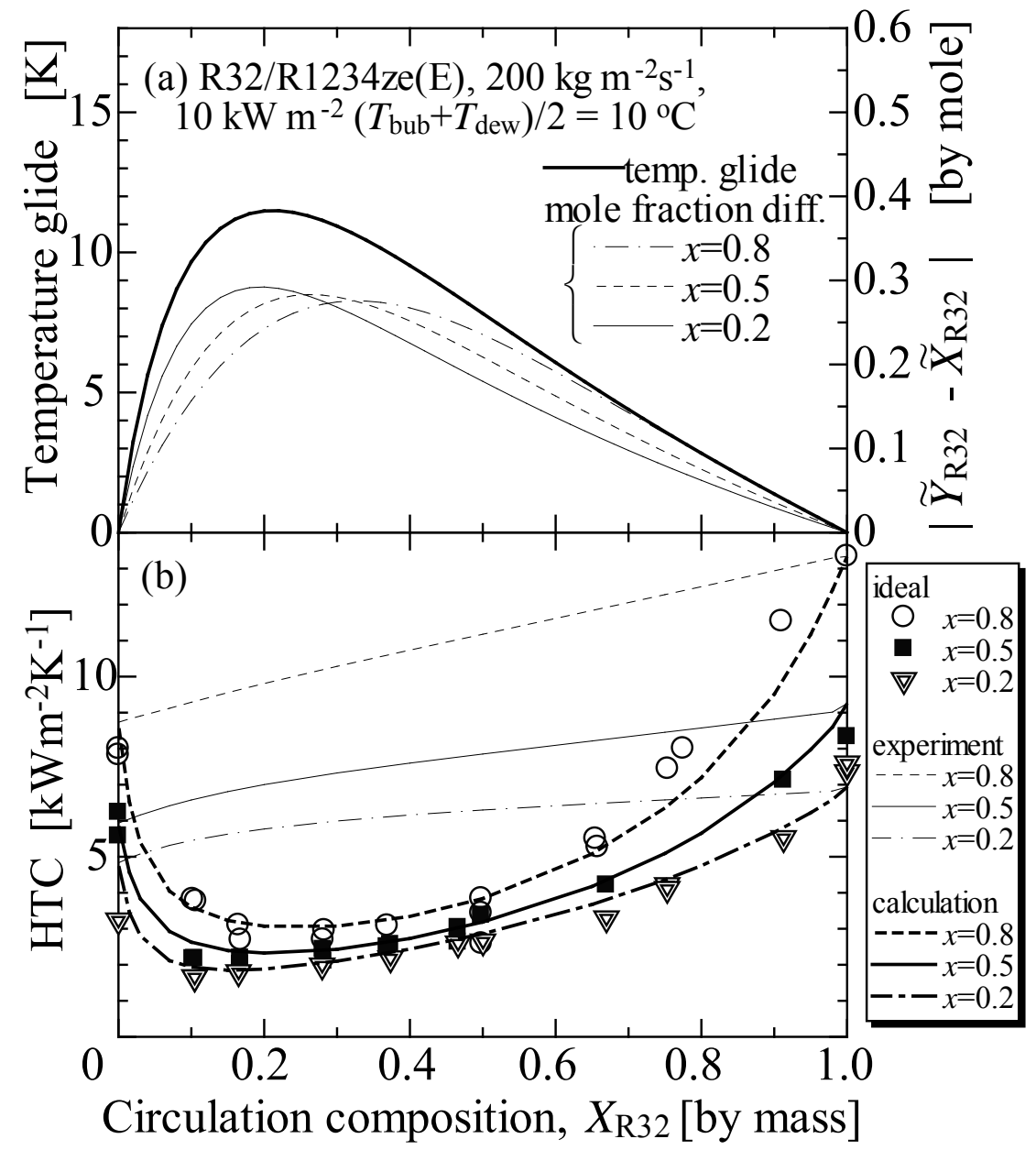

(b) evaporation heat tranfser at $10^{\circ} \mathrm{C}$ (The HTC are predicted by the correlation of Kondou et al. (2013).

Figrue 3 (Contitued). 


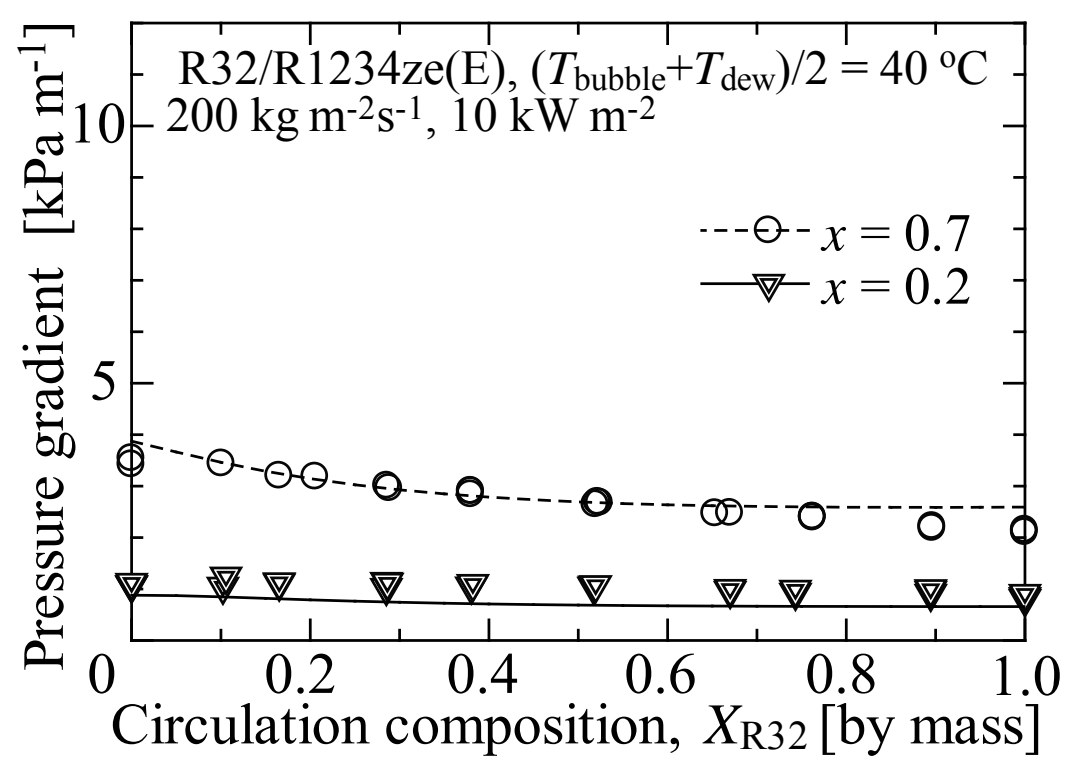

(a) Pressure gradient during condensation at $40^{\circ} \mathrm{C}$

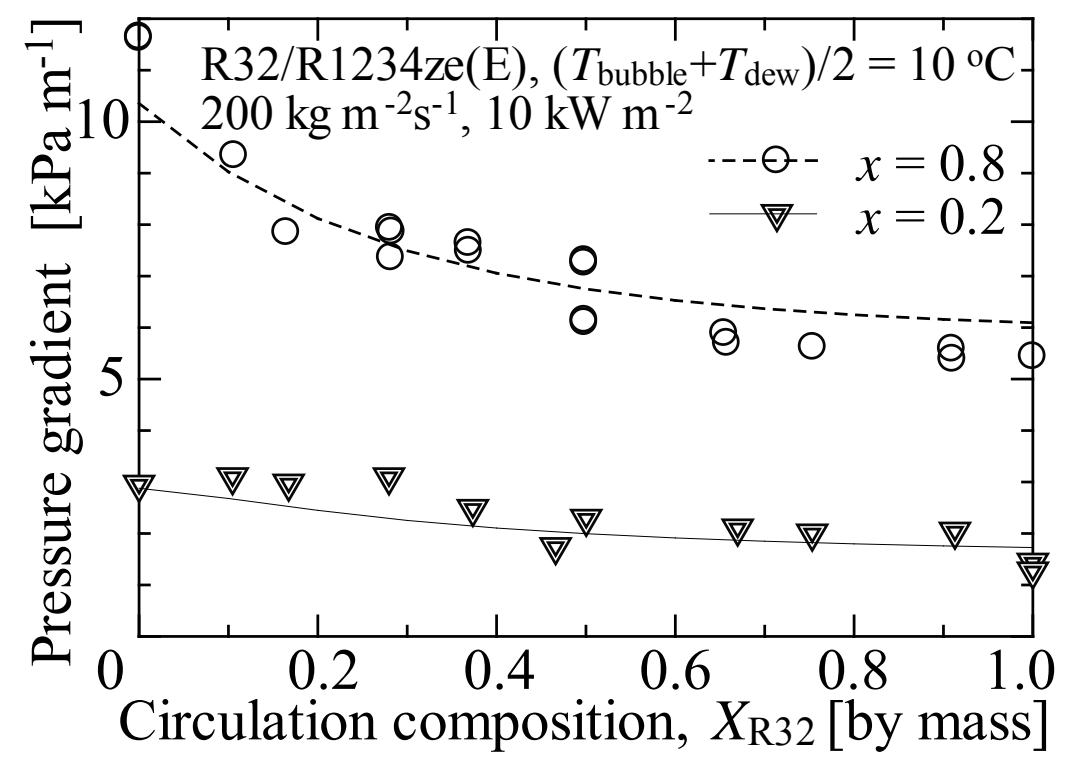

(b) Pressure gradient during evaporation at $10{ }^{\circ} \mathrm{C}$

Figure 4 Variation in the HTC of the binary mixture R32/R1234ze(E) against the circulation composition. 


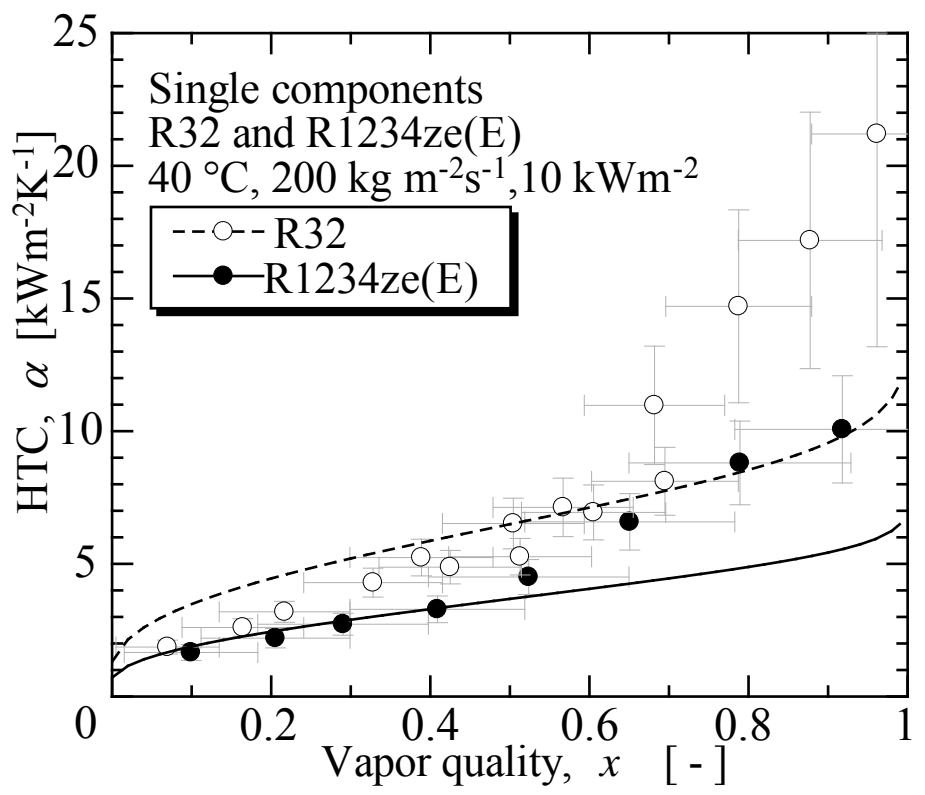

(a) Single components

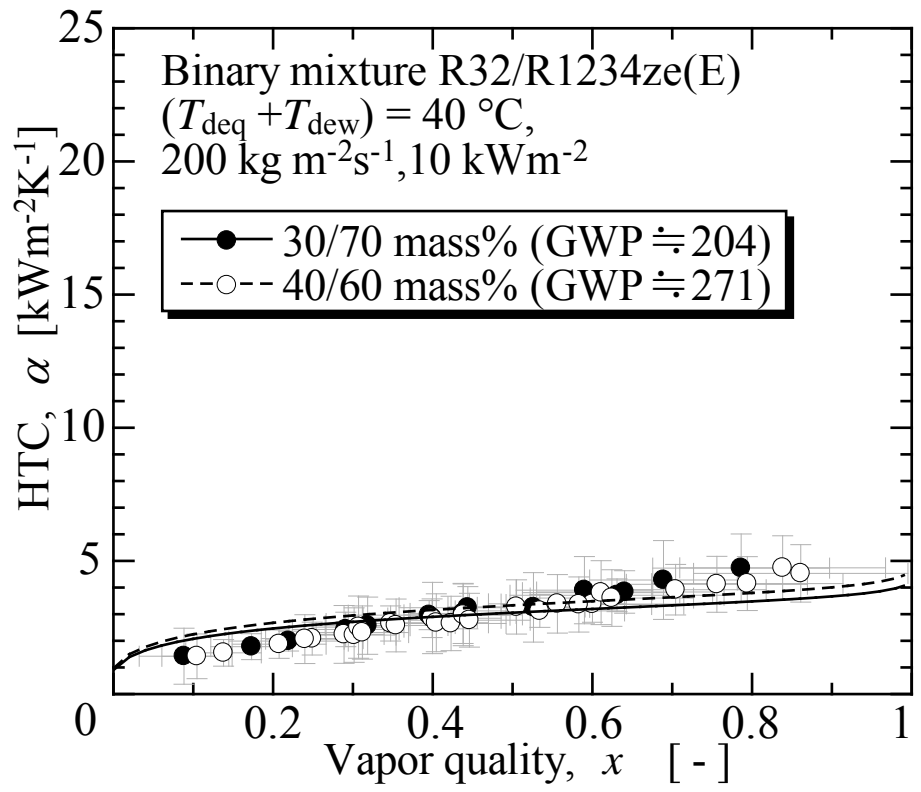

(b) Binary mixture R32/R1234ze(E)

Figure 5 Difference in condensation HTC between the single components and the mixtures (The lines are HTC predicted by correlations of Cavallini et al. (2009) with correction method of Silver-

Bell-Ghaly (1942, 1973). 


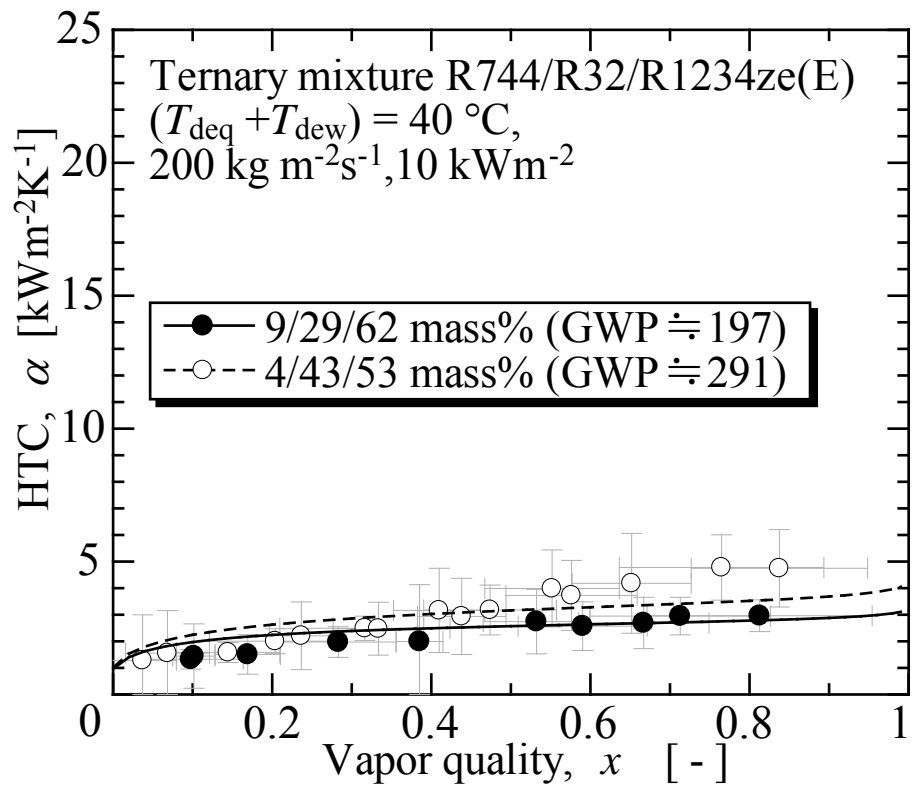

(c) Ternary mixture R744/R32/R1234ze(E)

Figure 5 (continued). 


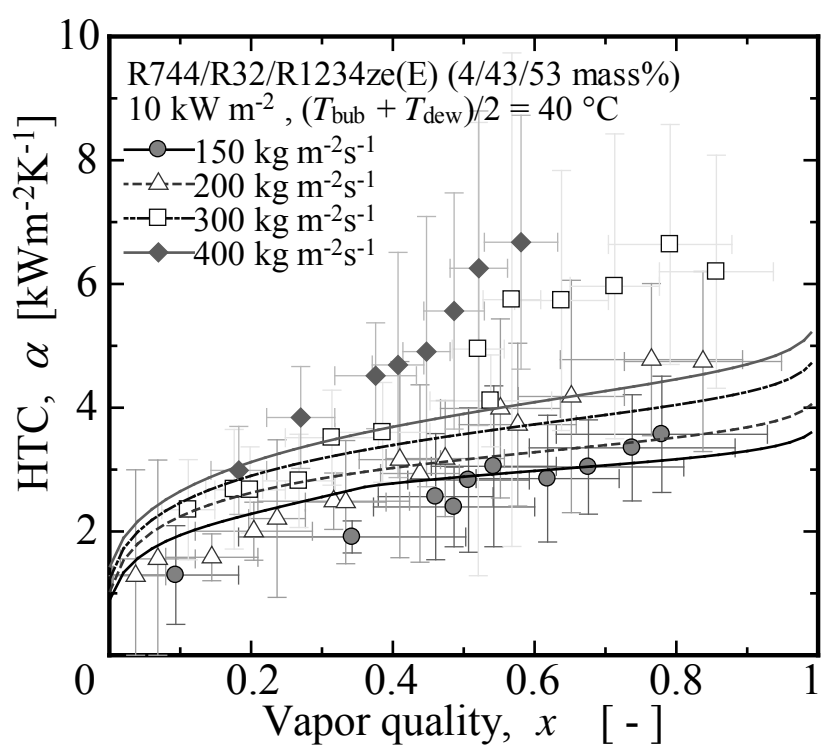

(a) $4 / 43 / 53$ mass $\%$

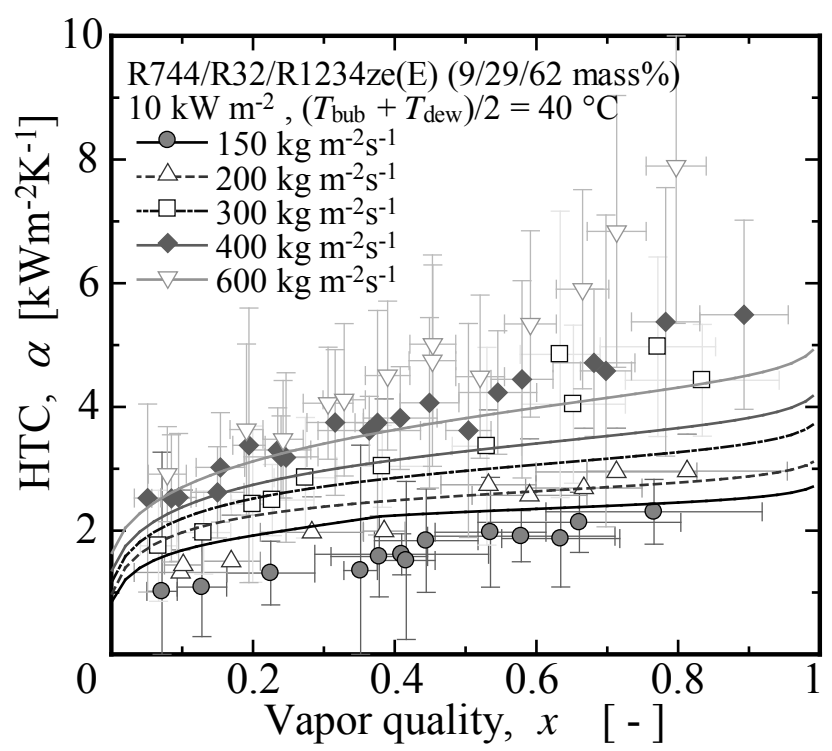

(b) $9 / 29 / 62$ mass $\%$

Figure 6 Mitigation of mass transfer resistance by increasing mass flux on the condensation HTC 


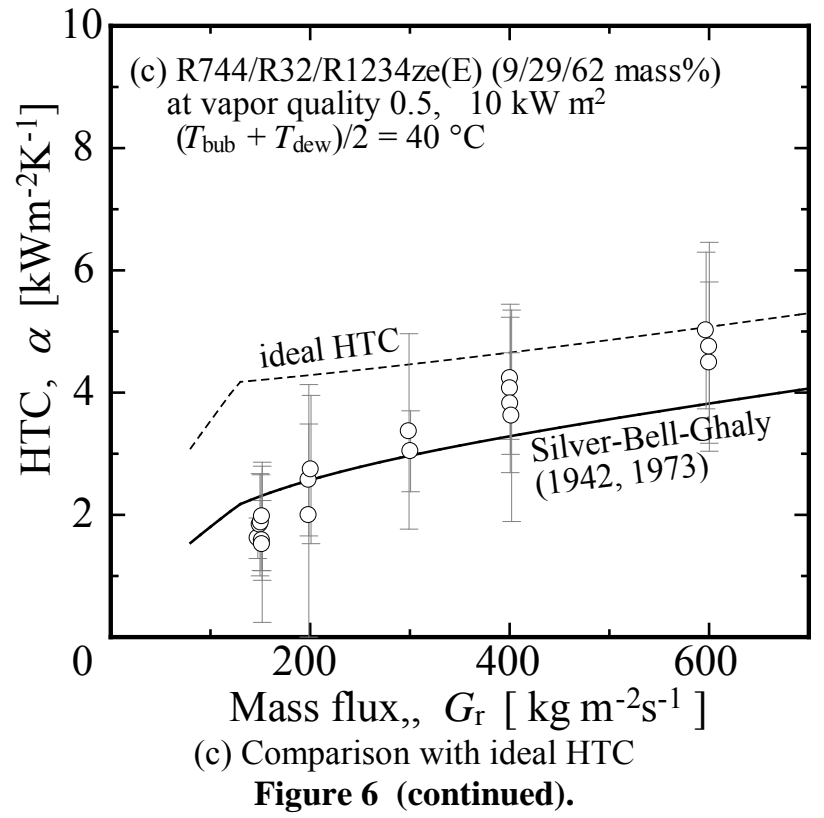




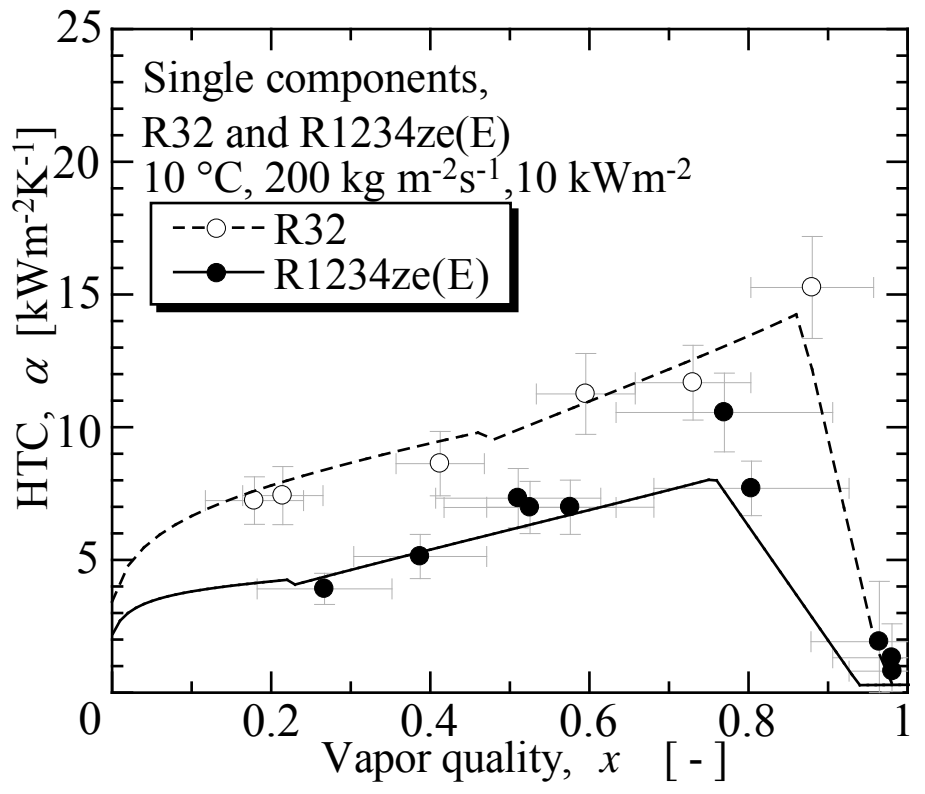

(a) Single components

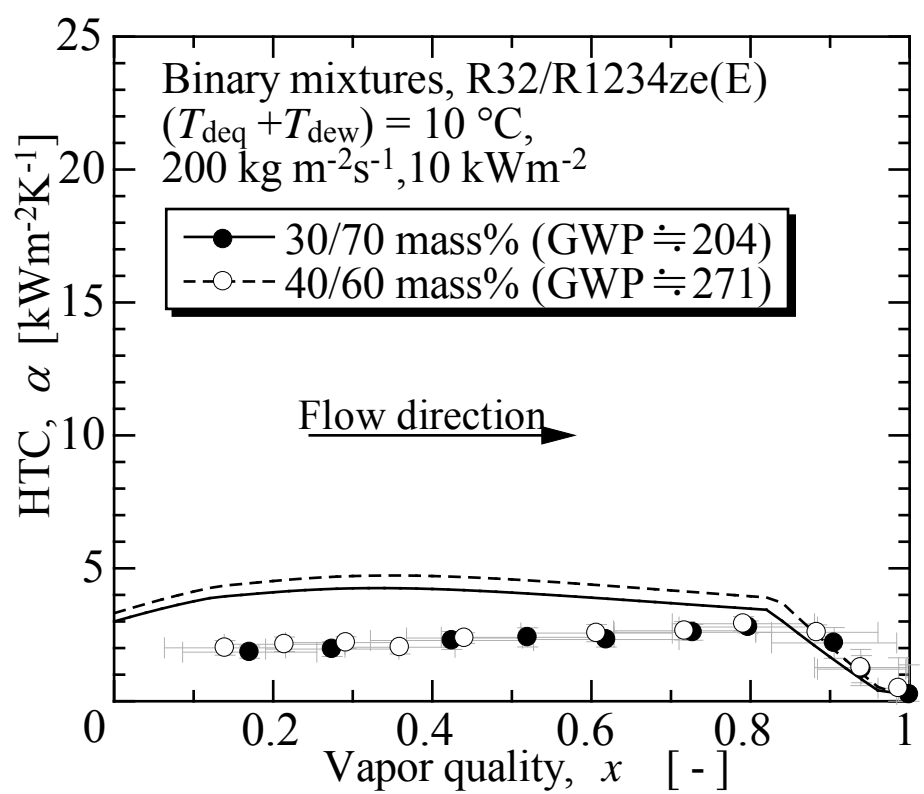

(b) Binary mixture R32/R1234ze(E)

Figure 7 Difference in the evaporation HTC between the single components and the mixtures (the lines are the HTC predicted by correlations of Mori (2002) for single components and Cavallini et al. (1998) for mixtures) 


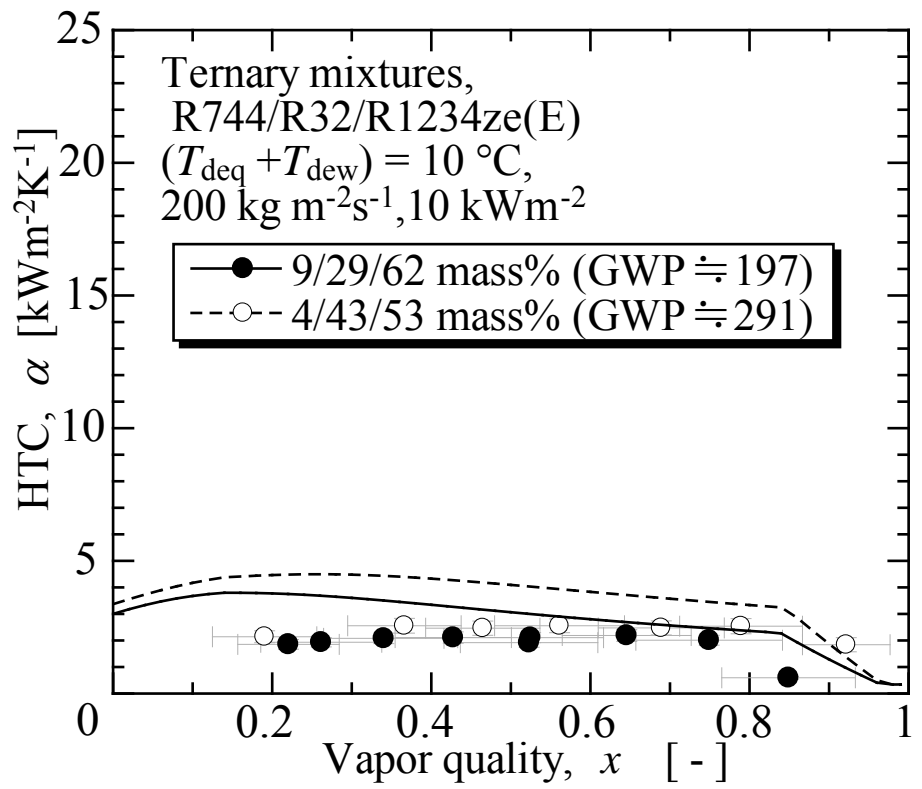

(c) Ternary mixture R744/R32/R1234ze(E)

Figure 7 (continued). 


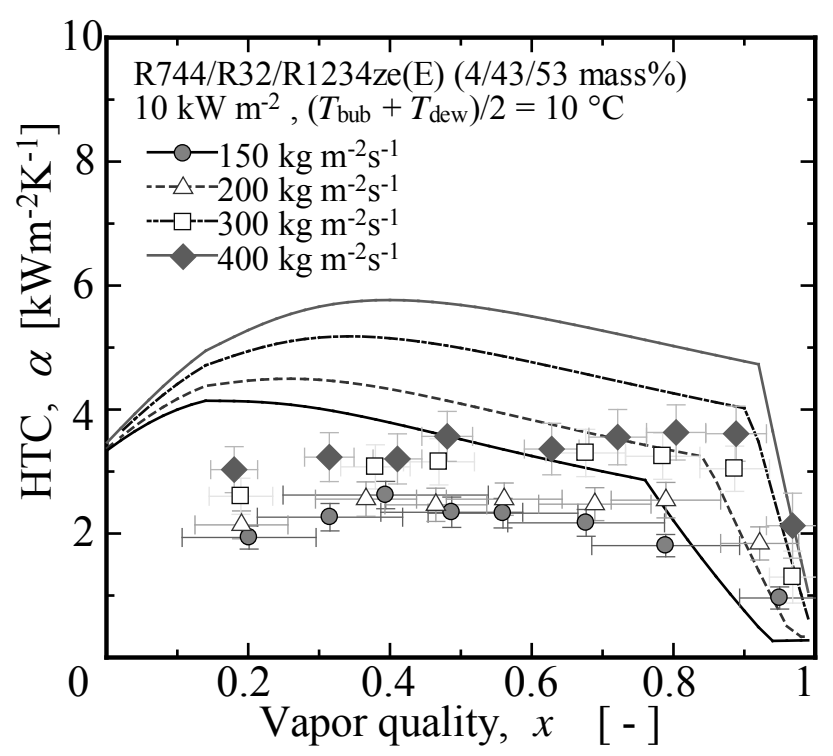

(a) $4 / 43 / 53$ mass $\%$

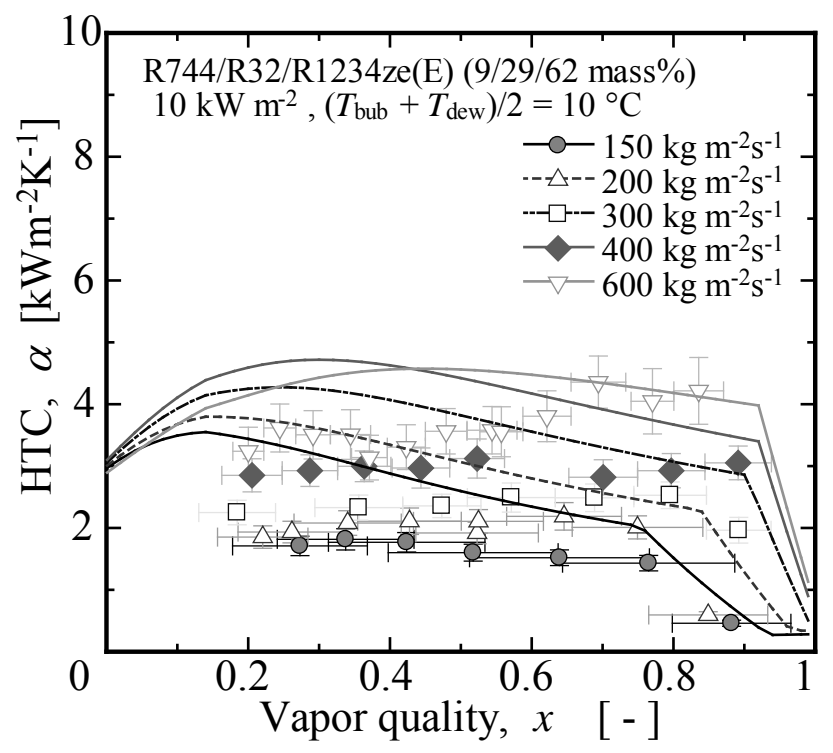

(b) $9 / 29 / 62$ mass $\%$

Figure 8 Effect of mass flux on mass transfer resistance on the evaporation HTC 


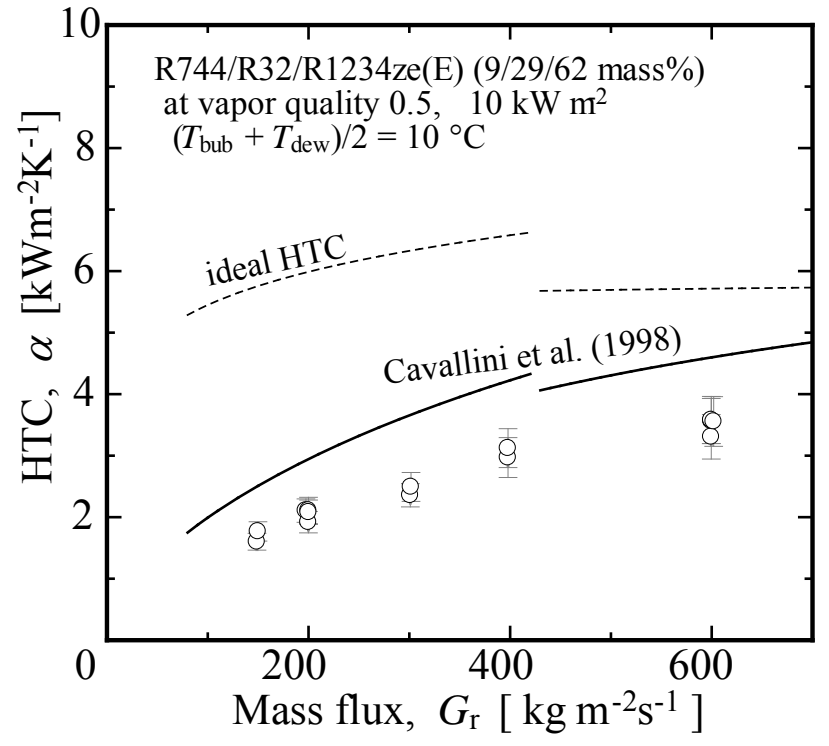

(c) Comparison with ideal HTC

Figure 8 (continued). 


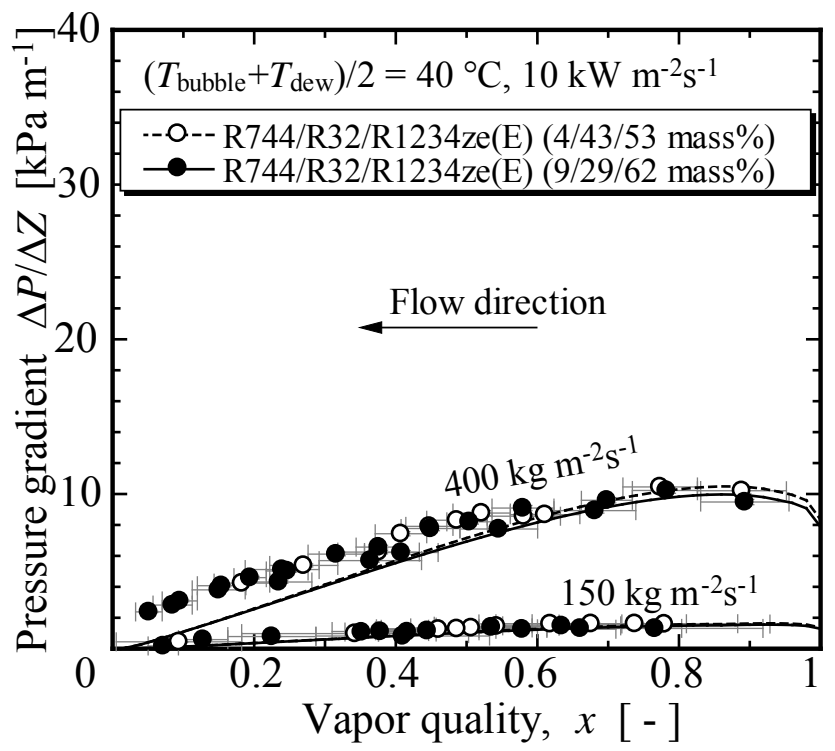

(a) Condensation at $40{ }^{\circ} \mathrm{C}$

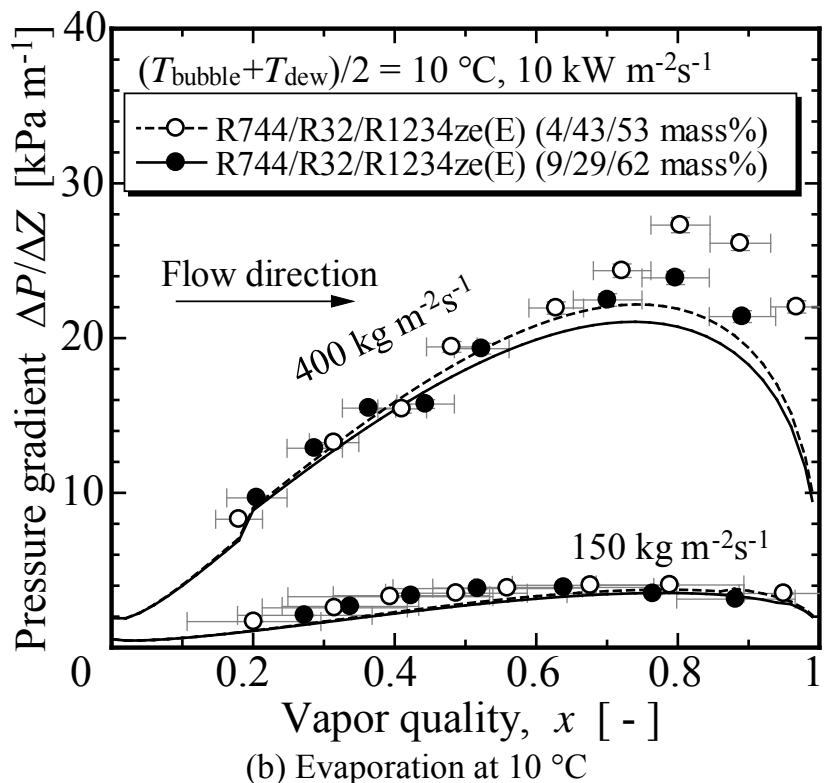

Figure 9 Pressure gradient of the ternary mixtures. (The lines are the prediction of YonemotoKoyama (2007) and Kubota et al. (2001) for condensation and evaporation respectively.) 


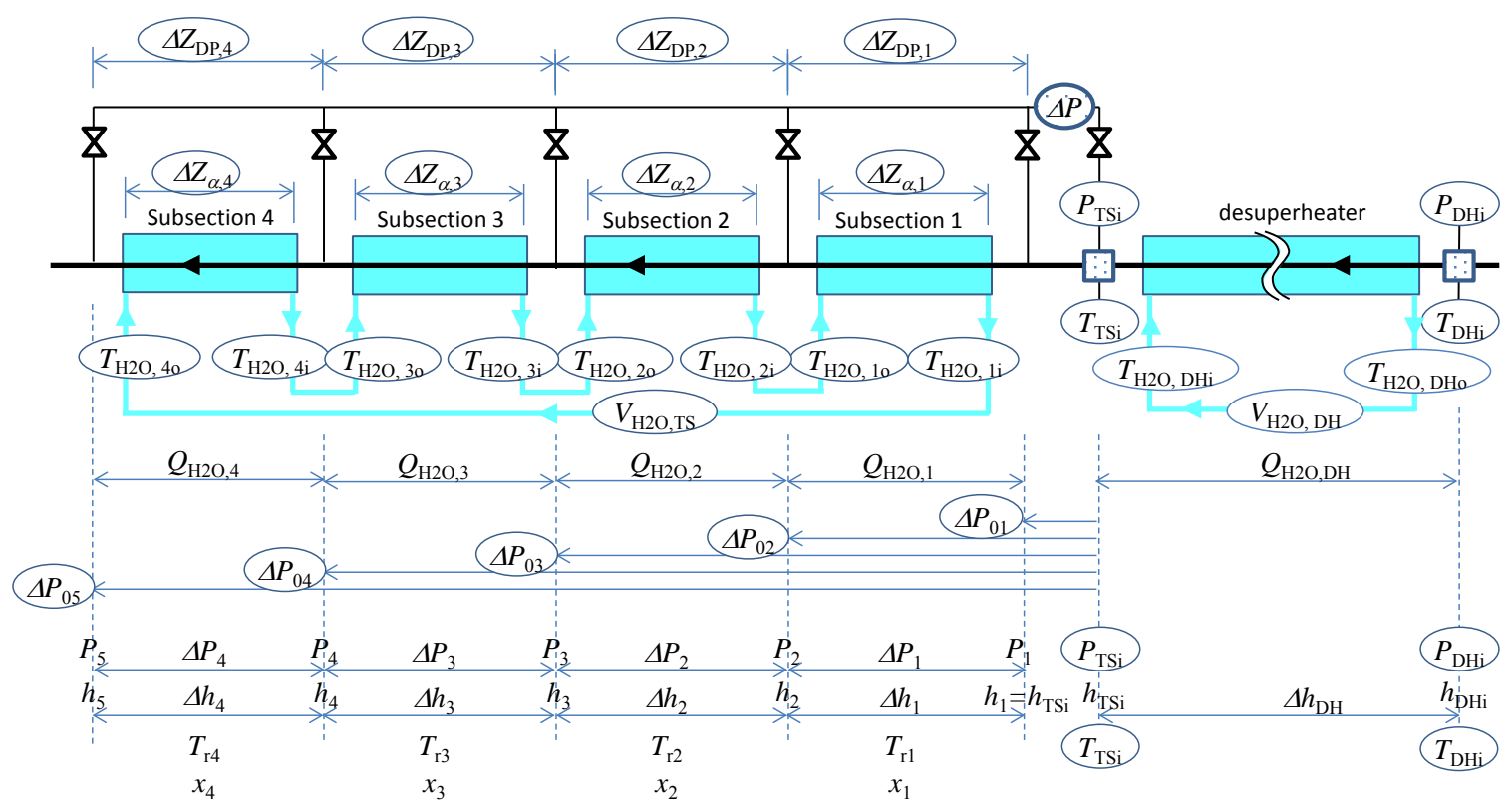

Figure A.1 Data reduction procedure for the condensation test 
Table 1: Dimensions of the test microfin tube

\begin{tabular}{lccc}
\hline Outer diameter & $D_{\mathrm{o}}$ & 6.0 & $\mathrm{~mm}$ \\
\hline Fin root inner diameter & $d_{\mathrm{max}}$ & 5.45 & $\mathrm{~mm}$ \\
\hline Equivalent inner diameter & $d_{\mathrm{eq}}$ & 5.35 & $\mathrm{~mm}$ \\
\hline Fin height & $h_{\text {fin }}$ & 0.255 & $\mathrm{~mm}$ \\
\hline Helix angle & $\beta$ & 20 & deg. \\
\hline Number of fins & $N_{\text {fin }}$ & 48 & - \\
\hline Surface enlargement & $\eta_{\mathrm{A}}$ & 2.24 & - \\
\hline
\end{tabular}

Table 2: Comparison on the thermophysical properties for the test refrigerants at equilibrium conditions

\begin{tabular}{|c|c|c|c|c|c|}
\hline & Refrigerant composition & $\begin{array}{l}\text { R32/1234ze(E) } \\
(30 / 70 \text { mass } \%)\end{array}$ & $\begin{array}{l}\text { R32/1234ze(E) } \\
(40 / 60 \text { mass\%) }\end{array}$ & $\begin{array}{c}\text { R744/32/1234ze(E) } \\
(9 / 29 / 62 \text { mass } \%)\end{array}$ & $\begin{array}{c}\text { R744/32/1234ze(E) } \\
(4 / 43 / 53 \text { mass } \%)\end{array}$ \\
\hline & $\mathrm{GWP}_{100} * \mathrm{a}$ & 207 & 274 & 200 & 293 \\
\hline \multirow{6}{*}{$\begin{array}{l}\text { * } \\
\text { U } \\
0 \\
\text { + } \\
\text { है }\end{array}$} & Pressure $[\mathrm{MPa}]$ & 1.44 & 1.62 & 1.94 & 1.90 \\
\hline & Temperature glide $[\mathrm{K}]$ & 10.3 & 9.0 & 18.7 & 11.8 \\
\hline & Latent heat of vaporization $\left[\mathrm{kJ} \mathrm{kg}^{-1}\right]$ & 187 & 194 & 199 & 201 \\
\hline & Density $\left[\mathrm{kg} \mathrm{m}^{-3}\right]^{* c}$ & $1056 / 59$ & $1031 / 62.4$ & $1042 / 73.7$ & $1015 / 69.8$ \\
\hline & Viscosity $[\mu \mathrm{Pa} \mathrm{s}] * \mathrm{c}$ & $136 / 13.9$ & $127 / 14.1$ & $131 / 14.8$ & $122 / 14.4$ \\
\hline & Thermal conductivity $\left[\mathrm{mW} \mathrm{m}^{-1} \mathrm{~K}^{-1}\right]^{* \mathrm{c}}$ & $86.6 / 16.3$ & $91.4 / 16.5$ & $91.2 / 18.0$ & $94.7 / 17.4$ \\
\hline \multirow{6}{*}{$\begin{array}{l}\stackrel{*}{*} \\
0 \\
0 \\
0 \\
\tilde{\sigma}\end{array}$} & Pressure [MPa] & 0.62 & 0.70 & 0.87 & 0.84 \\
\hline & Temperature glide $[\mathrm{K}]$ & 11.7 & 10.2 & 21.6 & 13.7 \\
\hline & Latent heat of vaporization $\left[\mathrm{kJ} \mathrm{kg}^{-1}\right]$ & 220 & 230 & 238 & 241 \\
\hline & Density $\left[\mathrm{kg} \mathrm{m}^{-3}\right]^{* \mathrm{c}}$ & $1168 / 24.9$ & $1146 / 26.3$ & $1161 / 32$ & $1134 / 29.8$ \\
\hline & Viscosity $[\mu \mathrm{Pa} \mathrm{s}] * \mathrm{c}$ & $194 / 12.5$ & $180 / 12.6$ & $191 / 13.1$ & $175 / 12.8$ \\
\hline & Thermal conductivity $\left[\mathrm{mW} \mathrm{m}^{-1} \mathrm{~K}^{-1}\right]^{* \mathrm{c}}$ & $101.4 / 13$ & $107.4 / 13$ & $108.4 / 14.2$ & $112.2 / 13.4$ \\
\hline
\end{tabular}

*a GWPs of mixtures are simply weighed GWPs of individual components by the mass fraction.

*b Average of dew and bubble temperatures.

*c These data at the equilibrium state are listed in the manner of "liquid / vapor".

Table 3: Comparison of the condensation HTC between experiments and correlations for single components

\begin{tabular}{l|cc|cc}
\hline \multirow{2}{*}{} & \multicolumn{2}{|c|}{ R32 } & \multicolumn{2}{c}{ R1234ze(E) } \\
& \multicolumn{2}{|c|}{$n=66$} & \multicolumn{2}{c}{$n=50$} \\
\cline { 2 - 5 } & $\bar{\varepsilon}$ & $\sigma$ & $\bar{\varepsilon}$ & $\sigma$ \\
\hline \hline Kedzierski and Goncalves (1999) & 0.11 & 0.29 & 0.28 & 0.25 \\
\hline Chamra et al. (2005) & -0.01 & 0.45 & -0.03 & 0.42 \\
\hline Yonemoto and Koyama (2007) & -0.09 & 0.32 & 0.05 & 0.25 \\
\hline Cavallini et al. (2009) & 0.13 & 0.37 & -0.01 & 0.28 \\
\hline
\end{tabular}


Table 4: Comparison of the condensation HTC between experiments and correlations for zeotropic mixtures

\begin{tabular}{l|cc}
\hline R32/R1234ze(E) $\quad(n=132)$ & $\bar{\varepsilon}$ & $\sigma$ \\
\hline \hline Cavallini et al. (2009) with Silver-Bell-Ghaly $(1942,1973)$ & 0.00 & 0.35 \\
\hline Chamra and Mago (2006) & 0.32 & 0.50 \\
\hline R744/R32/R1234ze(E) $\quad(n=123)$ & $\bar{\varepsilon}$ & $\sigma$ \\
\hline \hline Cavallini et al. (2009) with Silver-Bell-Ghaly (1942, 1973) & 0.01 & 0.33 \\
\hline Chamra and Mago (2006) & 0.27 & 0.41 \\
\hline
\end{tabular}

Table 5: Comparison of the evaporation HTC between experiments and correlations for the single components

\begin{tabular}{l|c|c|c|c}
\hline & \multicolumn{2}{|c|}{$\begin{array}{c}\text { R32 } \\
n=90\end{array}$} & \multicolumn{2}{c}{$\begin{array}{c}\text { R1234ze(E) } \\
n=44\end{array}$} \\
\hline & $\bar{\varepsilon}$ & $\sigma$ & $\bar{\varepsilon}$ & $\sigma$ \\
\hline \hline Momoki et al. (1995) & -0.04 & 0.23 & 0.11 & 0.36 \\
\hline Thome et al. (1997) & 0.02 & 0.18 & 0.18 & 0.46 \\
\hline Mori et al. (2002) & -0.01 & 0.17 & 0.13 & 0.45 \\
\hline Yun et al. (2002) & -0.04 & 0.31 & -0.41 & 0.33 \\
\hline Chamra and Mago (2007) & 1.01 & 0.51 & 0.92 & 0.92 \\
\hline
\end{tabular}

Table 6: Comparison of the condensation HTC between experiments and correlations for the zeotropic mixtures

\begin{tabular}{l|c|c}
\hline R32/R1234ze(E) $(n=189)$ & $\bar{\varepsilon}$ & $\sigma$ \\
\hline \hline Murata (1996) & 2.64 & 4.70 \\
\hline Cavallini et al. (1998) & 0.54 & 0.42 \\
\hline Chamra and Mago (2007) & -0.14 & 0.33 \\
\hline R744/R32/R1234ze(E) $(n=128)$ & $\bar{\varepsilon}$ & $\sigma$ \\
\hline \hline Cavallini et al. (2007) & 0.59 & 0.34 \\
\hline Chamra et al. (2006) & -0.20 & 0.21 \\
\hline
\end{tabular}


Table 7: Comparison of the pressure gradient between experiments and correlations for zeotropic mixtures

\begin{tabular}{l|c|c|l|c|c}
\hline \multicolumn{3}{c|}{ Condensation } & \multicolumn{3}{c}{ Evaporation } \\
\hline R744/R32/R1234ze(E) $(n=128)$ & $\bar{\varepsilon}$ & $\sigma$ & R744/R32/R1234ze(E) $(n=156)$ & $\bar{\varepsilon}$ & $\sigma$ \\
\hline \hline Cavallini et al. (1997) & 0.08 & 0.18 & Goto et al. $(2001,2007)$ & -0.38 & 0.14 \\
\hline Goto et al. (2001, 2007) & -0.42 & 0.11 & Newell and Shah $(2001)$ & -0.02 & 0.25 \\
\hline Yonemoto and Koyama (2007) & -0.24 & 0.22 & Kubota et al. $(2001)$ & -0.10 & 0.13 \\
\hline Newell and Shah (2001) & -0.35 & 0.21 & Filho et al. $(2004)$ & 0.50 & 0.19 \\
\hline
\end{tabular}

Table A.1 Measurement uncertainties.

\begin{tabular}{|c|c|c|c|}
\hline measurement points & & instruments, max. reading & uncertainty \\
\hline refrig. temp. & $U_{T_{\mathrm{r}}}$ & $\mathrm{K}$ type sheathed thermocouple, $\phi 1 \mathrm{~mm}$ & $\pm 0.05^{\circ} \mathrm{C}$ \\
\hline refrig. flow rate & $U_{W_{\mathrm{r}}}$ & Coriolis mass flow meter, Max. $50 \mathrm{~kg} \mathrm{~h}^{-1}$ & $\begin{array}{c} \pm 0.05 \mathrm{~kg} \mathrm{~h}^{-1} \\
(0.1 \% \text { of reading, zero } \\
\left.\text { stability; } 0.0072 \mathrm{~kg} \mathrm{~h}^{-1}\right)\end{array}$ \\
\hline refrig. absolute pressure & $U_{P}$ & absolute pressure transducer, Max. $1 \mathrm{MPa}_{\mathrm{abs}}$ & $\begin{array}{c} \pm 2 \mathrm{kPa} \\
(0.2 \% \text { of reading })\end{array}$ \\
\hline refrig. differential pressure & $U_{\Delta P}$ & differential pressure transducer, Max. $\pm 100 \mathrm{kPa}$ & $\begin{array}{c} \pm 0.3 \mathrm{kPa} \\
(0.3 \% \text { of reading) }\end{array}$ \\
\hline refrig. composition & $U_{X_{\mathrm{R} 32}}$ & TCD type gas-chromatograph & \pm 0.03 by mass \\
\hline tube wall temp. & $U_{T_{\mathrm{wo}}}$ & $\mathrm{T}$ type thermocouple, $\phi 0.127 \mathrm{~mm}$ & $\pm 0.05^{\circ} \mathrm{C}$ \\
\hline water temp. & $U_{T_{\mathrm{H} 20}}$ & $\begin{array}{l}\text { Pt resistance thermometer, } \phi 2.0 \mathrm{~mm} \\
(\mathrm{PT} 100 \Omega \text { 4wire-1mA) }\end{array}$ & $\pm 0.03{ }^{\circ} \mathrm{C}$ \\
\hline water flow rate & $U_{V_{\mathrm{H} 20}}$ & $\begin{array}{c}\text { gear type volumetric flow meter, Max. } 300 \mathrm{~L} \mathrm{~h}^{-1} \\
\text { (Oval, ECO OVAL, LGV45A30) }\end{array}$ & $\begin{array}{c} \pm 1.5 \mathrm{~L} \mathrm{~h}^{-1} \\
(0.5 \% \text { of reading })\end{array}$ \\
\hline
\end{tabular}

